\title{
Nuevos datos sobre la saga musical de los Acuña: el cantante, pianista y copista Josef Francisco Acuña y Castells (*Xàtiva, 1778)
}

\author{
New data on the Acuña musical saga: the singer, pianist, \\ and copyist Josef Francisco Acuña Castells (*Xàtiva, 1778)
}

\section{José Gabriel Guaita Gabaldón}

Universidad Politécnica de Valencia josguga@postgrado.upv.es ORCID iD: https://orcid.org/ 0000-0003-1383-471X

\section{RESUMEN}

Este artículo recupera información sobre la vida y la actividad profesional del músico setabense Josef Francisco Acuña (*1778) — no investigado en profundidad hasta ahora- a través del análisis y cotejo de diversas fuentes archivísticas, bibliográficas y hemerográficas. Se configura así un relato biográfico articulado teniendo en cuenta sus distintas etapas de actividad artística y su desempeño de diferentes oficios en varias ciudades de la península durante la primera mitad del siglo XIX. Se estudian, asimismo, los lazos profesionales que mantuvo con importantes figuras de su tiempo, como el cantante Manuel García, el librero y activista liberal valenciano Miguel Domingo y la familia Máiquez, además de elaborar un recuento de sus obras, compuestas y/o arregladas para las librerías valencianas y mallorquinas, y también del repertorio que interpretó durante su actividad como tenor y pianista en Madrid, Valencia y Palma de Mallorca.

Palabras clave: Acuña, Caños del Peral, Xàtiva, ópera española, canción patriótica. 


\begin{abstract}
This article shows the biographical details and the professional activity of the musician from Xativa (Valencia) Josef Francisco Acuña (*1778) (not studied until now) through the analysis and collation of various archival, bibliographic and press sources. In this way, a biographical story is configured, articulated through its different artistic stages, trades, and locations in various cities of the peninsula during the first half of the 19th century, linking it to important figures of his time such as Manuel García or the Maiquez family. Likewise, an account of his works composed for Valencian and Majorcan bookstores, as well as his concert activity as a tenor and pianist, is manifested.
\end{abstract}

Key Words: Acuña, Caños del Peral, Xativa, Spanish opera, patriotic song.

Guaita Gabaldón, J. G. (2022). Nuevos datos sobre la saga musical de los Acuña: el cantante, pianista y copista Josef Francisco Acuña y Castells (*Xàtiva, 1778). Cuadernos de Investigación Musical, (14), pp. 189-222.

\title{
1. Estado DE LA CUESTIÓN: NOVEDADES SObRe LA SAGA ACUÑa EN XÀTIVA
}

En 1996, María Concepción Peñas publicó un artículo en la Revista de Musicología dedicado a los Acuña, una relevante familia de músicos setabenses. Durante estos últimos años, otros autores han ido completando lagunas historiográficas y musicológicas existentes sobre los cuatro músicos de dicha estirpe conocidos actualmente (Peñas, 1996; Palencia, 1996; Capdepón, 1998; García, 2015; Pascual, 2020). Este artículo recupera la figura de un quinto miembro de dicha familia dedicado a la música y no investigado hasta el momento: Josef Francisco Acuña y Castells ${ }^{1}$, cantante, pianista, compositor de canciones patrióticas y copista de fortepiano que trabajó en Xàtiva, Madrid, Valencia y Palma de Mallorca durante la primera mitad del siglo XIX.

Oriundo de la localidad valenciana de Xàtiva, comenzó su carrera artística pública en 1800, aproximadamente, convirtiéndose a los veintidós años en uno de los cantantes de ópera ligera más famosos en los teatros de Madrid (Saldoni, 1881, IV, p. 8). A partir de ese momento su vida discurrió entre varias capitales de la Península Ibérica en las cuales desarrolló una trayectoria profesional multifacética relacionada con la música y el mundo de las compañías teatrales. Los datos de registro de su nacimiento en el libro de bautismos de la Colegial de Xàtiva, unidos a otras referencias documentales expuestas más abajo me han permitido además relacionarlo con el importante linaje de músicos apellidados Acuña, de Murcia y Xàtiva, activos en España desde el siglo XVIII.

\footnotetext{
${ }^{1}$ Según la fuente, nombrado indistintamente como Josef, Joseph o José. Mantengo la grafía Josef por ser la utilizada por él mismo al firmar un memorial, así como su obra Marcha Patriótica que se canta en el Exército Nacional del Reyno de Valencia [Fuego y sangre, españoles]. $\boldsymbol{E}-\mathrm{Mn}$ : R/62517.
} 


\section{NUEVOS DATOS SOBRE LA SAGA MUSICAL DE LOS ACUÑA: EL CANTANTE, PIANISTA Y COPISTA JOSEF FRANCISCO ACUÑA Y CASTELLS (*XàTIVA, 1778)}

En lo que respecta a los orígenes familiares, cabe decir que la documentación procedente de la tradición historiográfica a principios del siglo XX consideraba que la saga musical de los Acuña era natural de Elche (Ruiz de Lihory, 1903, pp. 3-4; Aguilar, 1983, pp. 366-368 [cits. en Peñas, 1996, pp. 182-183]); sin embargo, datos existentes en la actualidad ${ }^{2}$ permiten afirmar que sus primeros miembros, Fernando (*1690c; †1754) y Juan Acuña y Faxardo [Fajardo], procedían muy probablemente de Murcia. A los citados hermanos, que obtuvieron cierto renombre en el ámbito musical religioso del siglo XVIII, les sucedieron sus sobrinos, Juan y Joaquín Acuña y Escarche [Escache] $]^{3}$, ya establecidos en Xàtiva. La clave para reordenar este conglomerado biográfico se encuentra, precisamente, en los expedientes de limpieza de sangre para la primera tonsura, órdenes menores y diaconado de Joaquín Acuña y Escarche, y en los relativos a la primera tonsura de su hermano, Juan Acuña y Escarche, pues contienen importante información relativa a sus orígenes familiares. Sobre dichos datos pretendo profundizar para poder recuperar información sobre nuestro biografiado.

La saga Acuña tiene su origen en dos ramas ubicadas temporalmente en el siglo XVIII: una originaria de la localidad murciana de Lorca (Murcia) y otra natural de la capital murciana, la cual se trasladó a Xàtiva. Los primeros músicos de la saga son los clérigos Juan (fl. 1746) y Fernando Acuña Faxardo (*1690c; †1754), erróneamente considerados como nacidos en Elche $^{4}$, más su hermano Nicolás Acuña Faxardo (*Murcia 21.10.1708 [b. S. Andrés, 27.10.1708]). Estos tres eran hijos de Juan Manuel Acuña y María Remedio Faxardos [Fajardo] - procedentes de Murcia y que, posteriormente, según un testigo de la misma ciudad, constan como residentes en «San Phelipe» (Xàtiva) ${ }^{5}$.

El tercer hermano, un zapatero de nombre Nicolás Acuña y Faxardo, casó con Ángela María Escarche (*Málaga, 03.02.1713), hija del hornero Francisco Escarche y García (Lorca) ${ }^{6}$ y de Anna Gómez Alemán, natural de Almagro (Toledo) ${ }^{7}$. Ambos se trasladaron a Xàtiva en

\footnotetext{
${ }^{2}$ E-V A Archivo Diocesano: sig. 19/22, Expediente de Joaquín Acuña, de Xätiva, para recibir la tonsura, 1767; Ibid: sig. 24/10, Expediente de Juan Acuña, organista, natural de Xàtiva, para recibir la primera tonsura, 1768.

${ }^{3}$ En la documentación consultada aparece indistintamente un apellido u otro. Mantengo el primero, Escarche, por coherencia con el resto de las publicaciones que así lo citan.

${ }^{4}$ Juan de Dios Aguilar Gómez afirma que Juan de Acuña era natural de Elche, desde donde se trasladó a Valencia. Sobre sobre esta información, Manel García ya ha manifestado dudas razonables (García, 2015, pp. 60, 314, 331); además, el texto que figura en el título de una de las primeras composiciones de Juan Acuña «[...] compuesto a devoción de la Santissima Madre de la Seo de la ciudad de S. Felipe, antes Xativa, Por un efclavo de la Virgen Madre, hijo de dicha ciudad» (E-VAbv: sig. XVIII/1706(10), Mistico dragma [sic] musico, intitulado El pueblo venturoso : compuesto a denocion de N.tra S.ra de la Seo de la ciudad de S. Felipe, antes Xativa / por un esclavo de la Virgen Madre, hijo de dicha ciudad; puesto en concento musico por Juan de Acuña), confirma que procedía de Xàtiva. En Valencia desempeñó el cargo de maestro de capilla en la Parroquia de San Martín (publicó varios villancicos en 1759) y fue beneficiado de la de Santa Catalina Mártir, desde donde pasó al magisterio de la parroquia de los Santos Juanes. Aparte de componer música religiosa, que se conserva en las catedrales de Segorbe y Orihuela, escribió dos zarzuelas trágico-cómicas y varios oratorios (Aguilar, 1983, pp. 367 y ss.; cit. en Capdepón, 1998, pp. 203). Incidiendo en la cuestión, cabe subrayar también que las actas de la catedral de Albarracín se refieren a Fernando Acuña como «tonsurado de Murcia», no de Elche (Peñas, 1996, p. 183).

5 Thomás Jacinto Aliaga, de San Phelipe (Xàtiva), regidor en clase de nobles de la ciudad, afirmaba que conoció en la ciudad a Juan Manuel Acuña y a María Remedio, su consorte, y que los hijos del matrimonio fueron Nicolás y Juan Acuña. E-VA Archivo Diocesano: sig. 19/22, Expediente de Joaquín Acuña, de Xàtiva, para recibir la tonsura, 1767.

${ }^{6}$ Francisco fue titular del horno de la Caridad en Málaga, donde nació su hija, y más tarde se trasladó a Murcia. ${ }^{7}$ Era nieta a su vez de Juan Escarche $(* 05.04 .1694)$ y Ana García, por parte de padre, y de Miguel Gómez y Theresa Alemán, por parte de madre, todos ellos oriundos de Lorca. Tras la boda de Nicolás y Ángela María en Murcia,
} 


\section{JOSÉ GABRIEL GUAITA GABALDÓN}

1751c junto con sus respectivos progenitores ${ }^{8}$. De ellos nacería la segunda generación de músicos Acuña: los organistas Joaquín $\left(* 11.04 .1744^{9} ; \nmid 19.09 .1809\right)$ y Juan $(* 1749 ; \nmid 1837)$ Acuña y Escarche, más un tercer hijo, Fernando, también zapatero, padre del músico biografiado en este artículo, cuya existencia no estaba demostrada hasta el momento.

Respecto al primero de los hijos de Nicolás Acuña y Ángela Escarche, Joaquín Acuña y Escarche, hay que decir que, desde muy pequeño, según el testimonio del infanzón valenciano Josef Granell, vivió en Valencia a cargo de su tío paterno, Mosén Juan Acuña y Faxardo, y estudió música como infantillo en la capilla de San Martín, donde su mencionado tío ejercía como maestro de capilla. En 1766 marchó a Orihuela al obtener por oposición una plaza de violón con un sueldo de 50 libras «en atención a su particular habilidad» ${ }^{10}$, que empezaría a cobrar a partir de su primera tonsura ${ }^{11}$.

Dos años después, Joaquín Acuña y Escarche solicitó la concesión de órdenes menores y consiguió el subdiaconado en agosto de 1770 y, finalmente, el diaconado en Valencia en diciembre de ese mismo año. Opositó al órgano de la colegiata de Xàtiva en 1785 tras reclamar sin éxito la plaza «en atención a sus pasados servicios», cuando desempeñaba el cargo de organista en la Universidad de Canals ${ }^{12}$. Finalmente, Joaquín Acuña Escarche fallecía en Valencia siendo organista del Real Seminario del Corpus Christi el 9 de septiembre de 1809, suplido desde 1808, cuando cayó enfermo, por Antonio Lureta (Climent, 2002, p. 159).

Por su parte, el segundo hermano músico, Juan Antonio Manuel Pío Acuña y Escarche (*Xàtiva, 1749; †1837), organista natural de Xàtiva, recibió la tonsura en noviembre de 1768 y entró como organista en la iglesia de Altura (diócesis de Segorbe), tras haber pasado unos meses en Valencia. Fue elegido por oposición en un proceso realizado en mayo de dicho año por los organistas Alexos Torrent y Miguel Antonio ${ }^{13}$. En abril de 1777 se trasladó a Navarra para ejercer como organista y Maestro de Capilla de Roncesvalles (Andrés, 2015, p. 1031).

Una vez resumidos y clarificados los datos de la segunda generación de músicos conocidos, cabe decir que he podido confirmar a un tercer hijo de la familia Acuña-Escarche, hermano por lo tanto de los dos anteriores. Este fue Fernando Acuña Escarche, padre de nuestro biografiado ${ }^{14}$. Fernando Acuña, tercer hijo de Nicolás Acuña Faxardo y zapatero

\footnotetext{
${ }^{8}$ Según el citado testigo, aunque la partida de nacimiento de su primer hijo, Joaquín, indica que residían allí desde 1744c.

${ }^{9}$ No en 1749, como establece Ros (2001, pp. 17-18), que debe confundirlo con su hermano Juan.

${ }^{10}$ E-V A Archivo Diocesano: sig. 19/22, Expediente de Joaquin Acuña, de Xàtiva, para recibir la tonsura, 1767.

${ }^{11}$ Sus tíos, Mosén Juan y Mosén Fernando Acuña y Faxardo practicaron diligencias de limpieza de sangre y le procuraron su primer destino como beneficiado y organista de la villa de Alcoy en 1768.

12 E-XAT: 2.1.2-18, Actas Capitulares, 1784-1788, fol. 50. Asimismo, existen curiosos testimonios sobre la personalidad de Joaquín Acuña y Escarche que aseguran que mostraba comportamientos inapropiados para su cargo, como «alguna fogosidad de genio mal reprimido», y que mantenía «diferencias con los asistentes de la Iglesia»; también que era «algo falto de humildad» y «sobrado frecuente en conversar con personas del otro sexo». Véase $\boldsymbol{E}-V A$ Archivo Diocesano: sig. 183/12, Expediente de Joaquín Acuña, de Xàtiva, para recibir la tonsura, 1767; Ibid. sig. 28/2, Expediente de Joaquín Acuña, natural de Xàtiva y residente en Alcoi para recibir las cuatro órdenes menores y el subdiaconado, 1770; Ibid. sig. 28/3, Expediente de Joaquín Acuña, natural de Xàtiva y beneficiado en la iglesia parroquial de Alcoi, para ascender al Diaconado, 1770.

${ }^{13} \boldsymbol{E}-V A$ Archivo Diocesano: sig. 24/10.

14 Peña (1996, p. 192) afirma que Juan Acuña era el tercero de los hijos de Nicolás Acuña. Asimismo, la existencia de este segundo Fernando en la saga confirma la afirmación del sucesor de Fernando Acuña Faxardo en San Nicolás de Bari (Alicante), que aseguraba que Fernando Acuña Faxardo poseía «sobrinos de igual apellido y nombre» (Peña, 1996, p. 186).
} 


\section{NUEVOS DATOS SOBRE LA SAGA MUSICAL DE LOS ACUÑA: EL CANTANTE, PIANISTA Y COPISTA JOSEF FRANCISCO ACUÑA Y CASTELLS (*XÀTIVA, 1778)}

como él, tuvo con Vicenta María Castells y Antolí a Josef Francisco Acuña y Castells el tres de octubre de 1778, tal como consta en las fuentes de la Colegial de Xàtiva ${ }^{15}$. Además, tuvo a otros siete hijos, algunos de ellos muertos prematuramente: María Ana [Mariana] $(* 1760)^{16}$, Vicenta María (*1763), Fernando Dionisio (*1766), Vicenta $(* 1770)$, Vicenta Clara $(* 1772)^{17}$, Fernando $(* 1774)$ y María Ramona $(* 1782)^{18}$.

Por tanto, visto lo expuesto hasta ahora, puedo confirmar que el personaje protagonista de este artículo, Josef Francisco Acuña Castells, fue sobrino de los músicos setabenses Juan y Joaquín Acuña y Escarche y sobrino-nieto de los músicos Fernando y Juan Acuña y Faxardo (figura 1).

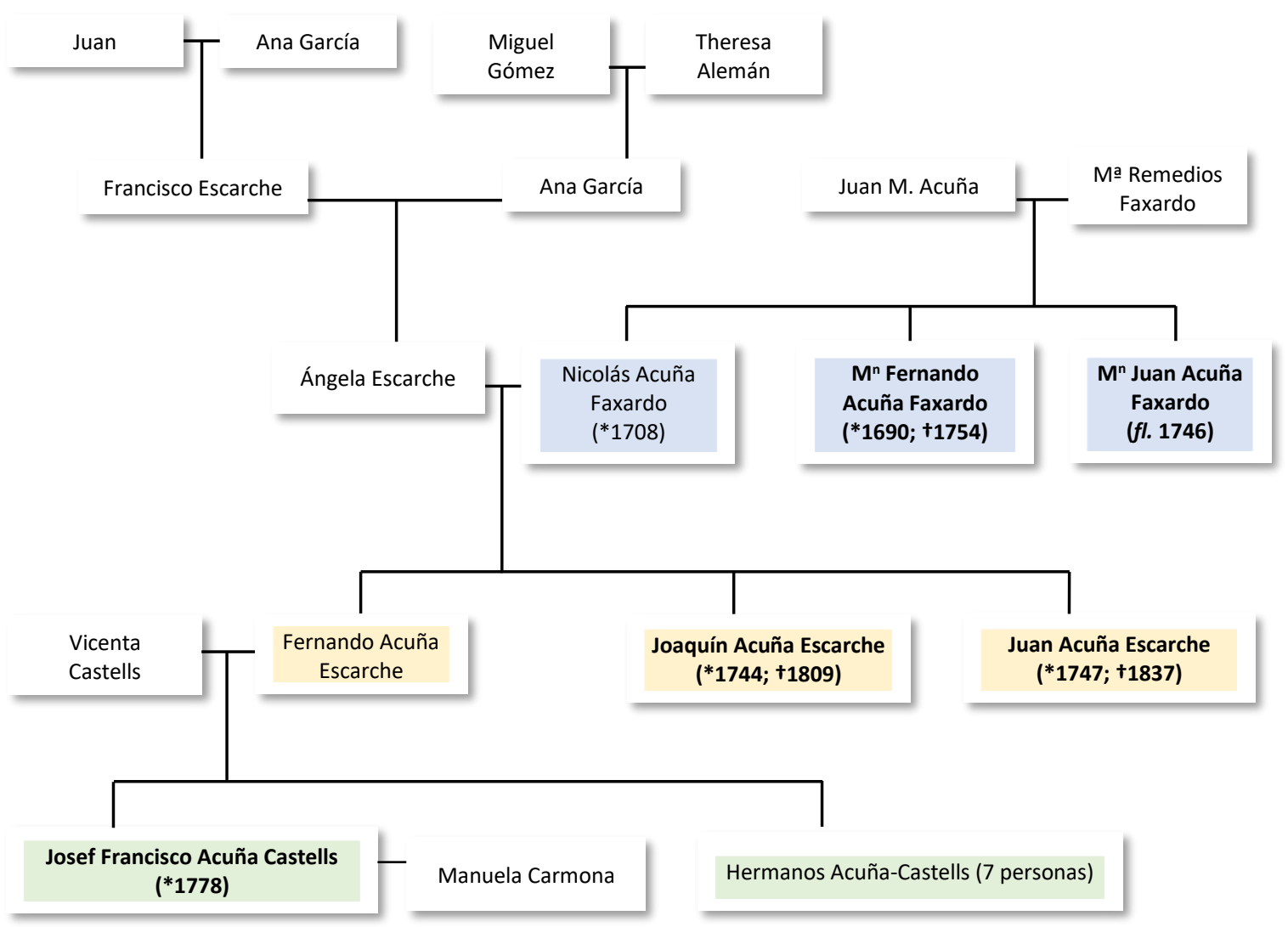

Fig. 1. Árbol genealógico de las familias Acuña y Faxardo, Acuña y Escarche y su vinculación con la familia Acuña y Castells en Xàtiva. En negrita los miembros vinculados con el mundo musical.

\footnotetext{
${ }^{15} \boldsymbol{E}$-VA Archivo Diocesano-Servicio De Archivos Parroquiales [SDAP]: Xàtiva-Asunción de Nuestra Señora, LB 1774-1799, fol. 60v.

${ }^{16} \boldsymbol{E}$-VA Archivo Diocesano-SDAP: Xàtiva-Asunción de Nuestra Señora, LB 1746-1761, fol. 386v.

${ }_{17} \boldsymbol{E}$-V A Archivo Diocesano-SDAP: Xàtiva-Asunción de Nuestra Señora, LB 1762-1773, fols. 45, 155v, 265, 319.

${ }^{18} \boldsymbol{E}$-V A Archivo Diocesano-SDAP: Xàtiva-Asunción de Nuestra Señora, LB 1774-1799, fols. 18, 61.
} 


\section{JOSÉ GABRIEL GUAITA GABALDÓN}

\section{ETAPA COMO TENOR EN LOS TEATROS DE MADRID, REALES Sitios Y VALLADOLID (1800-1808)}

Conviene reseñar previamente que nuestro biografiado tuvo un inmediato predecesor con el mismo apellido en los teatros de la península: Francisco Acuña. Se desconoce si procede también de la familia setabense de músicos, aunque sí que se corrobora su relación con Valencia — se le incluía, junto a su mujer, la tiple Jacinta Sánchez, en la lista de actores de una compañía madrileña que actuaba en la capital levantina en 1762-. Fue actor y apuntador, tanto en compañías provinciales como en la corte; entre 1769-1770 alcanzó su mejor momento profesional en la compañía de María Hidalgo actuando como segundo galán y sobresaliente en el teatro del Príncipe. Su actividad cesó pocos años antes de comenzar la de nuestro protagonista ${ }^{19}$.

Centrando ya el tema, cabe decir que Josef Francisco Acuña y Castells comenzó su andadura profesional a los veinte años. Desarrolló una prolífica carrera como tenor y actor de cantado en los teatros de la corte durante la primera década del siglo XIX, época en la que se implementaban diversos procesos de reforma en la organización teatral y nacionalización artística que permitieron el encumbramiento de figuras vernáculas de la tonadilla escénica y la ópera como Manuel García (Romero \& Moreno, 2006). Los éxitos obtenidos por La isla del placer de Vicente Martín y Soler $(* 1754 ; \nmid 1806)$ en su estreno (1799) y la gran aceptación que tenían las obras del españolizado Stefano Cristiani (*1770; †1825), influyeron en la idea de fomentar una escuela lírica española. Todo ello enmarcado en una época políticamente compleja que sentaba las bases para la transición hacia un estado moderno. En este sentido, el teatro fue uno de los espacios condicionadores y propagadores tanto del discurso político y estético, como de la discusión de temas relativas a la conformación de una nueva cultura musical moderna, como la formación musical de mujeres y hombres (Carreras, 2018, p. 286; Guaita, 2020, p. 203; Díez, 2009).

La Real Orden de 28 de diciembre de 1799, por la cual ningún teatro de España podía representar ni cantar piezas que no estuvieran en castellano y obligaba a que fueran interpretadas por actores nacionales, incentivó la composición de óperas bufas en castellano y promovió la castellanización de óperas italianas y francesas. También las grandes producciones de bailes pantomímicos en las que intervenían bailarines españoles favorecieron la consolidación profesional de actores y actrices de cantado autóctonos, que

\footnotetext{
${ }^{19}$ Francisco Acuña estaba casado, al menos desde 1745 con la actriz y tiple Jacinta Sánchez, que figuraba en 1741 como cuarta dama en una compañía de provincias. En 1746, Jacinta hacía de sexta dama en la de compañía de Petronila Jibaja, mientras que su marido realizaba discretos octavos papeles de galán. Hasta el 19.10.1762, trabajaron para la compañía de Águeda de la Calle en el teatro del Príncipe, Jacinta como parte por medio, y Francisco como apuntador. La temporada 1769-1770, Acuña se incorporó a la compañía dramática de los teatros de la corte como segundo galán y sobresaliente, por detrás de Manuel Martínez, abandonándola al final de la temporada. En 1781 volvió desde Guadalajara como segundo barba de la compañía de Martínez, en sustitución del primero, Manuel de Vera. Tras otra salida, en 1783 pidió volver a Madrid, alegando haber trabajado en la villa durante seis años como parte por medio, luego como primer apuntador y, después, de segundo galán durante dos años, pero no lo consiguió. Siguió actuando en provincias -en 1791 era primer barba de la compañía de Lázaro Calderi en Cartagena (Diario de Madrid, 28.04.1791)- hasta que presentó a la Junta de teatros un memorial pidiendo alguna renta en 1795 y, a modo de jubilación, se le conservó el sueldo de cuatro reales y medio que desde años venía suministrándole la compañía de Manuel Martínez (Cotarelo, 1899, pp. 450, $473,594)$.
} 


\section{NUEVos DATOS SOBRE LA SAGA MUSICAL DE LOS ACUÑA: EL CANTANTE, PIANISTA Y COPISTA JOSEF FRANCISCO ACUÑA Y CASTELLS (*XÀTIVA, 1778)}

pasaron a hacerse cargo de obras de gran formato lírico (véase Diana, 1850, pp. 42-45; Gómez Amat, 1984, pp. 103-130; Carreras, 2018, pp. 289-293; Casares, 2018) ${ }^{20}$. No obstante, el Teatro de la Santa Cruz de Barcelona logró evitar dicha prohibición, con lo que las compañías italianas en dicha ciudad continuaron funcionando.

Esta situación se unió a la desastrosa gestión económica y artística de los teatros de la Cruz y del Príncipe promovida por la fracasada reforma del censor Santos Díez, y las tácticas hostigadoras de la llamada Junta de Teatros o «Mesa Censora» del general Cuesta, Fernández de Moratín y el propio Díez, que sometieron —-mediante la consecución de diversas reales órdenes con varias amenazas ${ }^{21}$ - a numerosos actores, vetando en los teatros a Isidoro Máiquez en dos ocasiones a su regreso de París (Cotarelo, 1902, pp. 75 y ss.).

De esta manera, el empresario operístico Melchor Ronzi dio la alternativa en el teatro italiano de los Caños del Peral, que hasta la fecha había poseído una compañía de ópera italiana, una serie de actores y actrices dramáticos, de cantado y líricos liderados por Máiquez y la Prado que, o bien habían actuado en las compañías españolas de Francisco Ramos y Luis Navarro en los teatros del Príncipe y de la $\mathrm{Cruz}^{22}$, o eran nuevos. Un año y medio más tarde, un Ronzi triunfante sobre la Junta consiguió que le otorgaran el control de los tres teatros madrileños. Dirigiendo toda la atención al de los Caños del Peral, concentró en él toda la potencia operística, las granadinas hermanas Correa —-Lorenza ${ }^{23}$, Manuela y Laureana-, también, no sin cierta resistencia, al actor Isidoro Máiquez ${ }^{24}$, así como los tenores Manuel García, José Acuña, Juan Muñoz, Eusebio Fernández y Lázaro Calderi; en definitiva, «lo mejor que en hombres había resultado de la compañía de los Caños» (Cotarelo, 1902, p. 126).

Acuña debutó en la apertura del teatro de los Caños el 13 de junio de 1800 con la ópera bufa en dos actos La dama soldado, ó El amor dichoso, versión española de Luciano Francisco Comella y Vilamitjana $(* 1751 ; \nmid 1812)$ de la ópera La donna soldato (1792) de Giuseppe Gazzaniga (*1743; †1818), que estaba dirigida por Isidoro Máiquez. Posteriormente, nuestro biografiado compartió cartel con la esposa de Máiquez, Antonia Prado y con los antes mencionados Carlota Michelet, Mariana Galindo, el soldado reconvertido en tenor Juan Muñoz y los bufos Mariano Querol y Benito Torrellas (Subirá, 1973, p. 46). Durante este período, Acuña fue considerado, junto con Manuel García, uno de los célebres cantantes

\footnotetext{
${ }^{20}$ El predominio de artistas (cantantes y bailarines) autóctonos finalizó en mayo de 1808, cuando una compañía italiana que había actuado en Barcelona obtuvo permiso para representar en Caños del Peral (Carmena, 1878, pp. 39-40, 49-50, 54).

${ }_{21}$ Véase por ejemplo la R.O. de 6 de julio de 1800 o la de 30 de marzo de 1801.

22 Ambos teatros se alternaban dichas compañías; así, en 1798-1799, la de Francisco Ramos actuaba en el de la Cruz, mientras que la de Luis Navarro en el del Príncipe, situación que se revertió en la temporada de 17991800 .

${ }^{23}$ Lorenza (*1773; †1831) viajó a Italia en 1803, siguiendo los pasos de Isidoro Máiquez en 1799, inaugurando una exitosa carrera por Europa (Carreras, 2018, pp. 111-113).

24 Isidoro Máiquez (*Cartagena, 1768; †Granada, 1820) fue uno de los actores más célebres del panorama español del cambio al siglo XIX. Debutó en 1791 en el teatro del Príncipe, viajó a París pensionado para conocer al dramaturgo François-Joseph Talma y triunfó con el estreno de dramas de Shakespeare y otras obras clásicas. Exiliado a Francia en la guerra de la Independencia y devuelto posteriormente a España, redactó un reglamento teatral para la capital (1818). De ideología liberal, acabó sus días desterrado en Granada por desacato al negarse a representar una comedia del político Javier de Burgos, de mala calidad, donde murió al poco tiempo de iniciarse la revuelta liberal.
} 


\section{JOSÉ GABRIEL GUAITA GABALDÓN}

masculinos que cultivaban tonadillas y zarzuelas en los teatros de la corte (Diana, 1850, p. 45).

Asimismo, parte de la documentación recabada sobre Josef Francisco Acuña procede del fondo Barbieri conservado en la Biblioteca Nacional de España $(\boldsymbol{E}-\mathbf{M n})$. Su nombre aparece por primera vez en dicho archivo en un documento conservado que reúne unos apuntes para el vestuario otra representación de la nueva compañía de Ronzi en el teatro de los Caños del Peral, interpretando la ópera Elfrida (1792) de Giovanni Paisiello (*1740; †1816) el 15.12.1800, adaptada al castellano por el citado Comella:

Vestuario p $[a r] a$ la Opera seria intitulada La Alfrida.

Un vestido p[ar]a la Dama: debe ser bueno por ser Hija del Conde de Devonia, y estar casada con un valido del Rey. | Otro p[ar]a la $2^{\mathrm{a}}$., q[u]e es confidenta de la primera | Otro p[ar]a el Rey, que le hace Acuña $[\ldots]^{25}$.

Asimismo, Acuña actuó en uno de los papeles en una pequeña obra musical en un acto, Felipe y Juanita, en la función que significó el regreso de Máiquez a las tablas el 20 de junio de 1801. En aquel momento estaba contratado como primer tenor de la compañía de cantado y percibía por su trabajo unos considerables 21000 reales de vellón (rs. vn.) anuales (1825 rs. vn. mensuales) ${ }^{26}$. Junto a él actuaba Carlota Michelet (24000 rs. vn.), primera dama; Mariana Galino [Galindo] (15000 rs. vn.) y María Puyg [Puig] (15000 rs. vn.), segundas damas; y Benito Torrellas, primer bufo (22000 rs. vn.), entre otros ${ }^{27}$.

Acuña continuó formando parte de la compañía de ópera de los Caños del Peral, pero fue desplazado en el puesto de primer tenor en 1802 por Manuel García, que volvía de Málaga tras su estancia en prisión (Diario de Madrid, núm. 105, 18.04.1802, p. 431; figura 2). Asimismo, en la misma temporada de 1802 estaba contratado como galán de cantado titular adscrito al teatro de la Cruz, siendo su compañera Carlota Michelet. El cinco de junio de ese mismo año cantó en la representación del drama en tres actos de Comella Pedro el Grande, Czar de Moscovia (Cotarelo, 1902, p. 639).

En julio, el teatro del Príncipe se incendió, mientras que en agosto de aquel año Ronzi, ante la imposibilidad de pagar a los actores, declaró la quiebra y renunció al control de las compañías, ganándose la enemistad de la profesión ${ }^{28}$. Ante las gestiones de la nueva junta para reducir de tres a dos las compañías se produjo una remodelación de la que Acuña salió mal parado, ya que abandonó la empresa (Cotarelo, 1902, pp. 116 y ss.).

\footnotetext{
${ }^{25} \boldsymbol{E}-M n$ : sig. Mss 14054/4(56) (cit. en Olmos, 2017, vol. 11, p. 341).

26 Para hacerse una idea de lo que suponía esta cantidad, un fortepiano de mesa económico construido en Madrid por Francisco Fernández en 1795 costaba unos 2000 rs. vn., mientras Francisco Flórez ofrecía en 1799 pianos de mesa de importación inglesa de cinco octavas entre 3000 y 1700 rs. vn. Los pianos de mesa de lujo que el propio Flórez construía a finales del XVIII para la nobleza y la corte oscilaban en torno a los 10000 y los 20000 reales (véase Bordas, 1988). Asimismo, en el Madrid de 1795-1800, el salario medio de un trabajador cualificado del sector servicios oscilaba entre 4100 y 3400 rs. vn. anuales (Llopis y García, 2011).

${ }^{27} \boldsymbol{E}-M n$ : Mss 14550/10 (cit. en Olmos, 2017, vol. 11, pp. 513-514).

${ }_{28}$ Más tarde, Ronzi recaló en Barcelona, quizá debido a la permanencia de compañías italianas en sus teatros; sin embargo, volvió a quebrar allí antes de ser requerido por la administración de José I para su vuelta a la corte.
} 


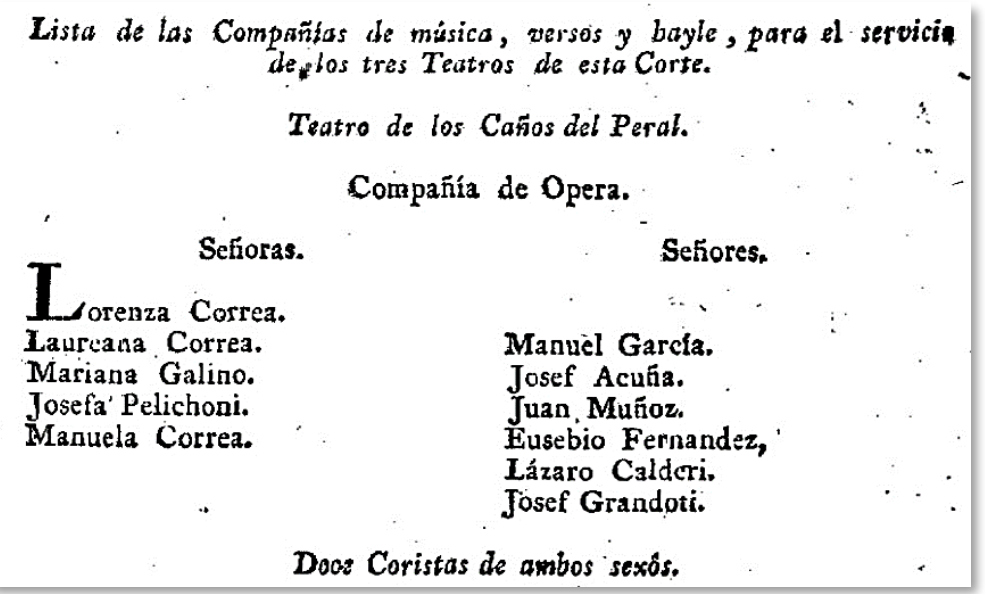

Fig. 2. Elenco de la compañía de ópera de los tres teatros de la corte en 1802 (Diario de Madrid, 105, 18.04.1802, p. 431).

Entre $1803^{29}$ y 1804, Josef Acuña no aparece en ninguna lista de actores de los teatros de la capital; sin embargo, se conservan sendas cartas fechadas en 1805 y 1806 a la Junta de Teatros que permiten comprobar que estuvo trabajando desde 1804 en la compañía de los Reales Sitios ${ }^{30}$ junto a su primera mujer, la célebre actriz Manuela Carmona $(* 1770 ; \nmid 1827)^{31}$. La nefasta relación entre la pareja le llevó, durante algún tiempo, a visitar el presidio, acusado por Manuela de algún asunto que no se explicita claramente en la documentación, presumiblemente de índole sexual, violento, o incluso político (Arregui, 2009, pp. 478, 480, 503).

La compañía de los Sitios estaba gestionada por el empresario Gregorio Bermúdez y el autor Luis Navarro, el cual había remozado los tres coliseos y dado un fuerte impulso a las representaciones en ellos (López de José, 2006, p. 469). Por lo que se desprende de la información obtenida, en este lapso, Acuña, actor de esta compañía, fue denunciado públicamente por su mujer y acabó entrando en presidio por un tiempo indeterminado. En 1804, siempre en palabras de Acuña, Manuela Carmona le amenazó reiteradamente con volver a enviarle a la cárcel o con amagos de otras cosas más graves, con lo que Acuña informó al mismísimo Godoy, Príncipe de la Paz, el cual le permitió salir de la compañía e instalarse en otro lugar. Así pues, Acuña rescindió el contrato que mantenía en los Reales Sitios y marchó a Valladolid, cediendo a la pretensión de Carmona de permanecer trabajando en los Sitios — no sin antes intentar apartarla del teatro e internarla en alguna institución eclesiástica-.

\footnotetext{
${ }^{29}$ En la cuaresma de 1803 comenzaron a representarse dramas sacros acompañados enmarcados en una suerte de conciertos espirituales por una gran orquesta (29 violines, siete violas, siete violones, siete contrabajos) en el coliseo de Caños del Peral, retomándose, después de la pascua, las representaciones teatrales. Más adelante, se reincorporó la compañía italiana, como va dicho, y la francesa de baile. Posteriormente se cerró dicho escenario debido a deficiencias estructurales hasta 1811, cuando se volvió a abrir pese a su mal estado para la realización de bailes de máscaras (Diana, 1850, pp. 46-48).

30 Sobre el teatro cortesano en los Reales Sitios de Aranjuez y san Ildefonso véase la tesis publicada de Alicia López de José (2006).

${ }^{31}$ Sirvienta y discípula de Rita Alfonso [Rita Luna] (*1770; †1832), Manuela Carmona había ejercido junto a su maestra ya en el coliseo de la Cruz en la temporada 1804-1805 (Cotarelo, 1902, p. 196).
} 


\section{José GABRIEL GuAita GABALDÓN}

En Valladolid, Acuña contrató con el autor Juan Ángel Peñalver —antiguo apuntador de la compañía de los Reales Sitios. Sin embargo, el marqués de Fuerte-Hijar, Germano de Salcedo y Somodevilla, subdelegado de teatros, le reclamó para que retornara a Aranjuez junto a su mujer (López de José, 2006, p. 469).

Ante la llegada inminente de la orden, Acuña envió una solicitud oficial a la Junta de Teatros exponiendo su caso y solicitando que no se le obligase a reunirse con su mujer, aduciendo que con ello se privaba a la compañía del teatro de Valladolid del único galán de música que poseía:

Josef Acuña único Galan de Música de este teatro ante V.S. digo: que por este Correo se escribe al Empresario por su apoderado Josef Soto que en este correo viene una õrn [orden] del Señor Marqués de Fuerte Hijar para que yo marche á unirme con mi mujer Manuela Carmona, cuyo precepto no puedo en justicia y en conciencia ejecutar por las muchas graves causas que para ello tengo y la constan á mi mujer, debiendo por ahora hacer presente á V.S. con el mayor respeto: que en virtud de las continuas y pesadas desavenencias que en todo el año anterior sufrió por el genio de su mujer Manuela Carmona hasta llegar el caso de haberse quejado aquella sin ningún motivo y por su poderío sufrido el exponente un sonrojo publico, á que jamás habría dado lugar por su mucho sufrimiento y prudencia, conociendo el altanero y sobervio genio de su mujer, que no contenta con no prestar á su Marido la justa y debida sumisión, que se debe en materias graves, trataba de amenazarle ya con que tenia en su mano el hacerme poner en un Presidio, ó ya con amagos de obra $\&^{a}$ que á la verdad, Señor, á no haber desde luego propuestome sufrir y padecer hasta acabar el año Cómico, podrían haber puesto en movimiento á el hombre más pacífico. De todo esto informé verbalmente al Excmo. Sor. Príncipe de la Paz que me libertó de volver al sonrojo de la Prisión, y no desaprobó la futura voluntaria separación en que yo pensaba, como único medio de librarnos uno ý otro de nuestra perdición: conclui pues la contrata que teníamos hecho en los Rs. Sitios y la propuse colocarme yo en otro destino, ya por los teatro ó bien en una Yglesia para mantenerla y experimentar de este modo si quitada del teatro cedia en su genio y colmaban nuestras desazones, á lo que se negó obstinadamente, y aunque por toda ley yo estaba en el caso de exigir que ocupándome en mi profesión y manteniéndola se la obligase a seguirme, quise corresponder sus repetidas instancias á cerca de que la diese mi consentimiento para ajustarse en los Sitios por este año, y que to me ajustase en otra parte, y que de no hacerlo así me buscaría por todos los medios mi perdición, y que no cesaría hasta conseguirlo, por todo lo que, llevado de un buen zelo y deseoso de no propagar los escándalos que se habían dado, di mi consentimiento por escrito al Empresario del Sitio al respaldo de su escritura para que se ajustase en aquella Compañía; convenimos en que yo me ajustase en otra parte, vino mi Muger á Madrid conmigo, no se trató de cosa en contrario, se volvió al Sitio y yo quedé a buscar mi acomodo; el Empresario de los Sitios ajustó otro Galan de Música, y yo me coloque en esta Compañía donde he sido admitido y tratado con el mayor agrado, y donde es necesario cumpla como hombre de bien mi contrato, pues nunca me persuado que un Juez trate de contemplar el capricho de una mujer en un perjuicio tan notorio de la Empresa que quedaba perdida y el Pueblo incomodado y sin arbitrio de devolver el crecido préstamo que he tomado ni menos subsanar los daños y perjuicios, ni tampoco puedo esperar que en virtud de mi justa y veraz exposición se haga conmigo una violencia de la que puedan resultar lastimosas consecuencias, fuera de que hallándome yo con $50 \mathrm{r}^{\mathrm{s}}$ de diario que es muy suficiente para mi decente manutención y con esperanza no 


\section{NUEVos DATOS SOBRE LA SAGA MUSICAL DE LOS ACUÑA: EL CANTANTE, PIANISTA}

Y COPISTA JOSEF FRANCISCO ACUÑA Y CASTELLS (*XàTIVA, 1778)

infundada de colocarme en alguna Catedral de Organista, ni debo perder esta mi subsistencia que por mi la tengo, ni ir a hacer el ridículo y escandaloso papel de ser mantenido por mi mujer, ni una colocación igual á la que tengo y á que está tan cercana la que he dicho de por vida: por cuyas razones espero de V.S. en caso de que venga la orden se sirva exponerlo así a la Superioridad, y de que en caso necesario estoy pronto a sostener la Justicia de mi resistencia à la reunión a lo menos por ahora en el tribunal competente. Valladolid a 13 de Abril de 1805.

Josef Acuña $a^{32}$.

En el mismo memorial, el autor Peñalver también suplicaba, afirmando que acababa de tener noticia por su apoderado en Madrid de que se iba a despachar orden de que Acuña volviese con su mujer y solicitaba que ésta no se produjese, ya que él no tenía las culpas «de las Camorras del matrimonio» o de «una voluntariosa queja de la Mugen», que perdería el préstamo y su empresa quedaría expuesta a la ruina. Asimismo, apelaba al superintendente general, alegando que conocería que Manuela Carmona había querido realmente dar un «golpe de Magestad pa . con su marido tan fuera ya de tiempo $\mathrm{q}^{\mathrm{e}}$. no solo resulta en perjuicio de tercero, sino $\mathrm{q}^{\mathrm{e}}$. $\tan$ bien en desagrado de un Publico, y q $\mathrm{q}^{\mathrm{e}}$. esto si en quanto al Marido hay lugar de $\mathrm{q}^{\mathrm{e}}$. se le sufriere, me parece no le habrá $\mathrm{p}^{\mathrm{a}}$. un Pueblo, y un Empresario [...]».

Sin embargo, el marqués de Fuerte-Hijar fue tajante, oficiando al corregidor de Valladolid para que mandase a Acuña a reunirse con su mujer apenas encontrase un sustituto en el teatro para él, además de ordenarle reprenderle por el «calor con que se ha producido en algunas expresiones de su escrito» ${ }^{33}$.

No obstante, en 1806 Acuña consiguió volver a formar parte de la compañía del teatro del Príncipe (Sepúlveda, 1888, pp. 457-458), que actuaba en los Caños del Peral interinamente, compartiendo cartel como segundo con Manuel García, Laureana Correa ${ }^{34}$ y Joaquina Sitches (conocida como «la Briones»). En esta segunda etapa actuó bien en óperas y y óperas bufas como El Delirio, o los efectos de un vicio, de Henri Montan Berton (Diario de Madrid, núm. 119, 29.04.1806, p. 524) y El Marinerito, atribuida a Vicente Rodríguez de Arellano (Diario de Madrid, núm. 243, 31.08.1806, p. 264 y núm. 244, 01.09.1806, p. 268), bien como cantante de la tonadilla tras la obra dramática (Diario de Madrid, núm. 95, 06.04.1806, p. 424).

\footnotetext{
$32 \boldsymbol{E}$-V Archivo Municipal de Valladolid: expedientes de actividades culturales (3 11 1 1), teatro, sig. 308-58, Cartas de Josef Acuña y Juan Ángel Peñalver a la Junta de Teatro.

$33 \boldsymbol{E}$-V Archivo Municipal de Valladolid: expedientes de actividades culturales $(31111$ 1), teatro, sig. 308-82, Carta de Josef Acuña a la Junta del Teatro.

${ }^{34}$ La cual trabajó en Valencia entre 1814 y 1815 (Diario de Valencia, núm. 100, 10.04.1814, p. 293).
} 


\begin{tabular}{|c|c|}
\hline 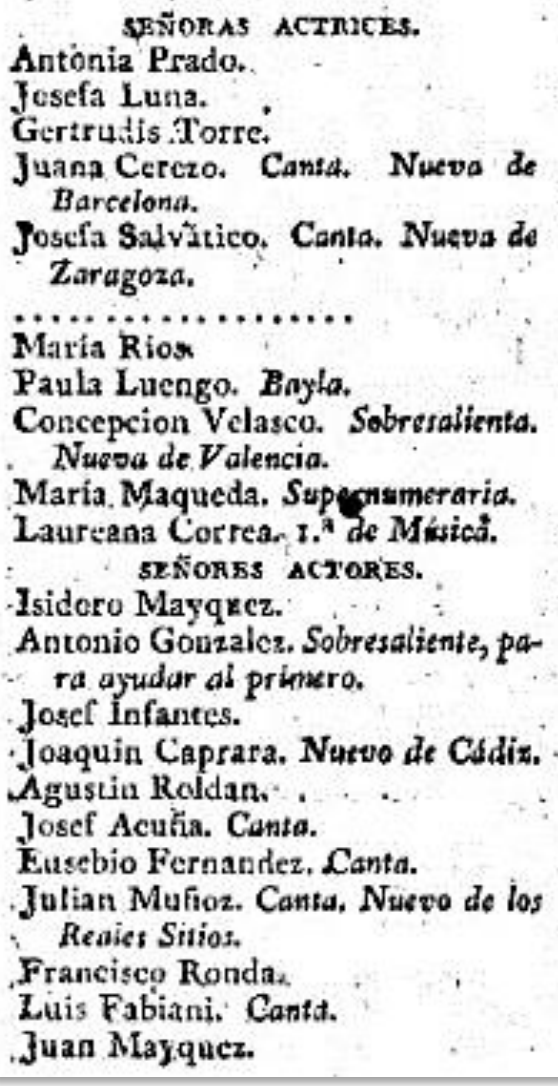 & 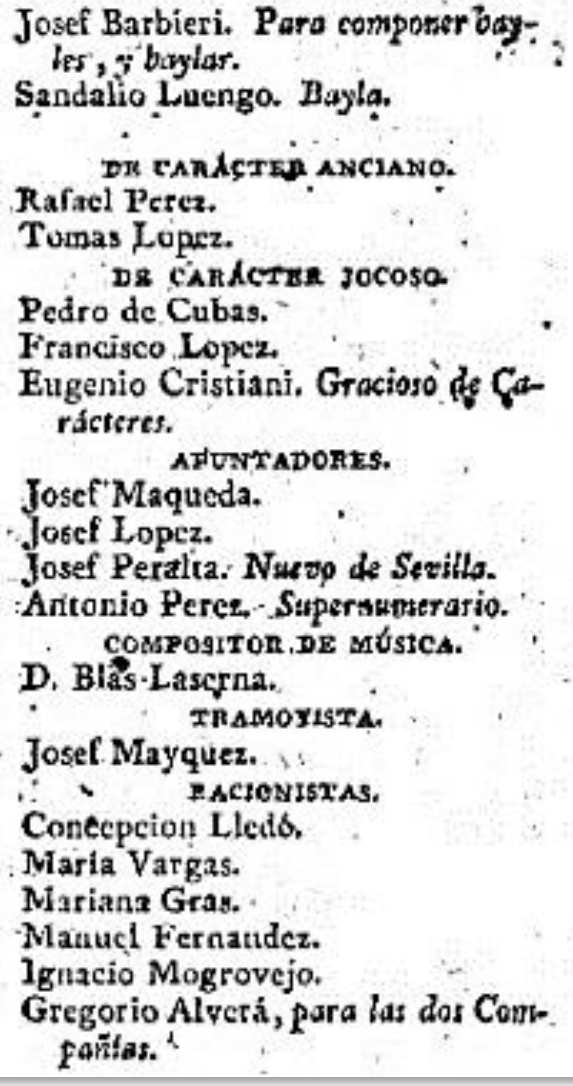 \\
\hline
\end{tabular}

Fig. 3: Elenco de la compañía del teatro del Príncipe para el año cómico de 1807 (Diario de Madrid, núm. 84, 25.03.1807, p. 249).

Acuña también fue durante estos años actor de comedias (Diario de Madrid, núm. 359, 25.12.1806; p. 738) y primera voz — cuando Manuel García se ausentó- en obras como Pamela Casada [Maritata] de Félix Enciso Castrillón (Diario de Madrid, núm. 339, 05.12.1806; p. 658), en la que actuó como bajo (Carmena, 1878, p. 55 y 425), constatando de nuevo las prodigiosas características de su voz y su amplio registro que hacían de él un cantante de gran versatilidad, tal y como se desprende de la referencias de sus conciertos posteriores, que se analizan en el epígrafe 4. En 1807 siguió cantando en producciones como Pícaros y Diego, ópera en un acto del mismo Enciso, que representó la compañía reunida en los Caños del 1 al 10 de enero de 1807 (Cotarelo, 1902, p. 245). También fue protagonista junto a la Prado en la reposición de Felipe y Juanita (Diario de Madrid, núm. 203, 22.07.1807, p. 92) en el teatro del Príncipe y en el de la Cruz; así como en las óperas El Engañador engañado (Diario de Madrid, núm. 237, 25.08.1807, p. 236), Finura astucia y embrolla, ó la Posadera sutil (Diario de Madrid, núm. 132, 12.05.1807, p. 564), obra en dos actos atribuida a José María de los Reyes Francesconi y Suffó (Fernández, 2009, pp. 50 y ss.) nuevamente con Laureana Correa, Francisca Briones ${ }^{35}$ y Eugenio Cristiani (hermano del afamado compositor Stefano Cristiani).

\footnotetext{
${ }^{35}$ Nacida de apellido Sitches, hermana de Joaquina Sitches, «la Briones».
} 


\section{NUEVos DATOS SOBRE LA SAGA MUSICAL DE LOS ACUÑA: EL CANTANTE, PIANISTA} Y COPISTA JOSEF FRANCISCO ACUÑA Y CASTELLS (*XàTIVA, 1778)

Con respecto a esta última, Finura astucia y embrolla, ó la Posadera sutil [La Astucia embrollada], conviene especificar que Acuña cantó el papel de Marqués (tenor) y que presentó un recibo el 29 de septiembre de 1807 porque había trabajado en ella durante su período de descanso: en concreto cobró 800 reales por el «trabajo extraordinario de la ópera [...] [que] se ejecutó en tiempo de mi parada» (Andioc y Coullon, 2008, cit. en Fernández, 2009, p. 50); ello ha llevado a plantear que Acuña fuese el autor de la música (Saura, 2008, p. 214), aunque en la partitura vocal ofrecida por Fernández (2009, p. 51) se especifica que su autor era Francesconi. Finalmente, la última ópera en la que participó Acuña fue la pieza en dos actos La Isabela, junto a la Prado, representada el 14 de diciembre de 1807 (Cotarelo, 1902, p. 686).

Acuña destacó también como solista en los dramas sacros y oratorios representados en la corte en tiempo de cuaresma. Destacable es su actuación en 1807 en El Sedecias, o Jerusalén destruida por Nabucodonosor, de Comella ${ }^{36}$, (Cotarelo, 1902, pp. 210-212; Diario de Madrid, núm. $54,23.02 .1807$, p. 224) interpretando los papeles del general Rabsaces — tenor- (figura 3) y de Nabucodonosor — bajo- indistintamente (Fernández, 2009, p. 56), dando prueba de un extraordinario rango de tesitura que se mostró posteriormente en sus conciertos a solo. También en la cuaresma de 1807 fue el actor de cantado del elenco para el drama religioso de Manuel Ventura Las maravillas de Dios por el brazo de Josué. Drama sacro en dos actos (Cotarelo, 1902, p. 275; Saura, 2008, p. 213).

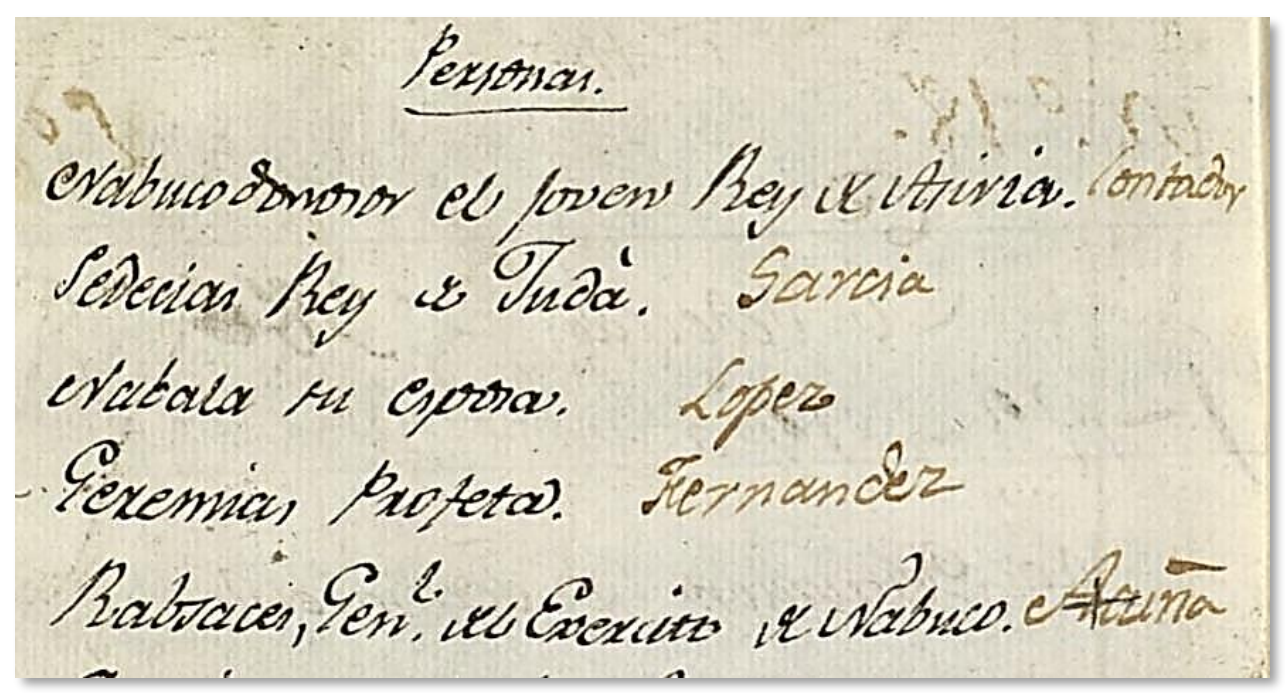

Fig. 4. Elenco del drama sacro El Sedecías, o Jerusalén destruida por Nabucodonosor (1805) en el que aparece Acuña junto a Manuel García, entre otros. $\boldsymbol{E}-M b$ : Tea 1-193-12.

\footnotetext{
${ }^{36}$ Estrenado el 24.03.1805 en el Teatro Caños del Peral (Andioc y Coullon, 2008, II, p.845). Obra compuesta en dos actos, con cuatro voces masculinas solistas — dos tenores y dos bajos- y una femenina — soprano-, además de coro de hombres y gran orquesta (Fernández, 2009, pp. 45-47).
} 


\section{JOSÉ GABRIEL GUAITA GABALDÓN}

En marzo de 1808 (días 6 al 10), Josef Acuña intervino en cuatro conciertos de música realizados en el teatro del Príncipe, sustituyendo la función que, al parecer, no se había podido poner a punto. En el tercer y cuarto concierto - martes y miércoles (8 y 9 de marzo)ejecutó, aparte de arias y dúos cantados, un concierto para fortepiano compuesto por él mismo.

No pudiéndose verificar en el teatro del Príncipe la función dispuesta, á las 5 de la tarde se executará un Concierto de música, difidido en dos partes. En la 1. ${ }^{a}$ se principiará con una sinfonía, seguirá una aria que cantará la Sra. Lledó, un duo entre la Sra. Carlota Michelet y el Sr. Acuña, una aria el Sr. Muñoz, otra el Sr. Eusebio Fernández, y un quinteto entre los cinco referidos sujetos. $=$ En la $2^{a}$. se tocará una sinfonía, cantará una aria el Sr. Acuña, un duo entre la Sra. Lledó y Acuña, una aria la Sra. Carlota, y un cuarteto la Sra. Carlota, Acuña, Muñoz y Eusebio. La entrada de ayer fue de 2041 y la de antes de anoche de 1127.

Nota. Deseoso Josef Acuña de manifestar el agradecimiento que profesa á tan respetable público por los favores que le ha dispensado, ofrece dar un concierto de forte-piano, composición suya. Si sus tareas merecen su indulgencia, será un estímulo para en lo sucesivo mostrar su reconocimiento» (Diario de Madrid, núm. 69, 09.03.1808, p. 308).

Después de la celebración de estos conciertos no se tiene constancia de actividad escénica alguna en Madrid hasta que, en 1812, Acuña Castells volvió a ser anunciado como nuevo integrante de la compañía cómica de Isidoro Máiquez que actuaba en el teatro del Príncipe (Diario de Madrid, núm. 34, 24.03.1812, p. 340; Sepúlveda, 1888, pp. 461-462); sin embargo, no se incorporó nunca (Cotarelo, 1902, p. 559). En abril del mismo año de 1808, las desavenencias y envidias remotas entre los aliados del galán Antonio González e Isidoro Máiquez y su mujer, Antonia Prado, provocaron la ruptura de negociaciones con el marqués de Perales y la salida de Máiquez y toda su troupe — Laureana Correa y Acuña, entre ellosde Madrid hacia provincias. Como nota curiosa, la sustituta de la Prado fue la ex mujer de Acuña, Manuela Carmona, quien llegó a la compañía por orden del Ministro de Policía probablemente por el asunto con Josef Acuña-, siendo primera actriz y jefa de la compañía ya en 1809 y empresaria en relación con Gregorio Bermúdez, antiguo empresario de los Reales Sitios $^{37}$, entre 1810-1811 (Thomason, 2005, pp. 175-176, 178).

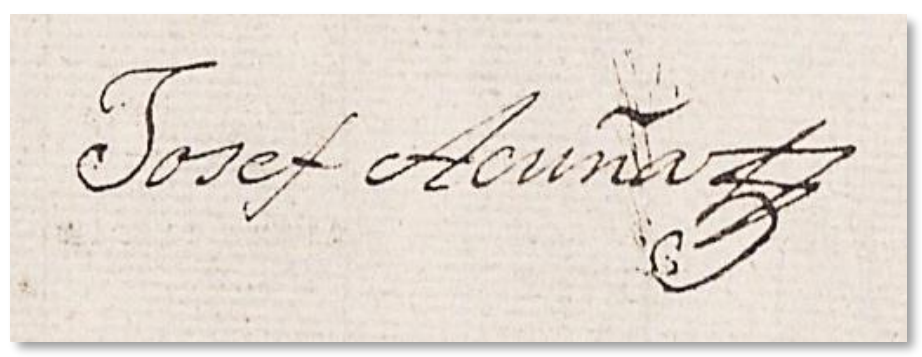

Fig. 5. Firma de Josef Acuña en el memorial presentado a la Junta de Teatros en 1806.

\footnotetext{
${ }^{37}$ La compañía de los Reales Sitios fue suprimida por el Reglamento general para la dirección y reforma de teatros que S.M. se ha servido encargar al Ayuntamiento de Madrid por su Real órden de 17 de Diciembre de 1806: aprobado por otra de 16 de Marzo de 1807.
} 
NUEVOS DATOS SOBRE LA SAGA MUSICAL DE LOS ACUÑA: EL CANTANTE, PIANISTA Y COPISTA JOSEF FRANCISCO ACUÑA Y CASTELLS (*XàTIVA, 1778)

\section{ACUÑA EN EL REINO DE VALENCIA: TENOR EN XÀTIVA, CONCERTISTA DE VOZ Y PIANO Y COPISTA DE MÚSICA DURANTE LA GUERRA DE LA INDEPENDENCIA (1810-1811).}

Mientras tanto, Josef Acuña reapareció en Valencia en 1810 y en Palma de Mallorca en 1812, afirmando en su publicidad de la última ciudad (1812) que había sido tenor en la Colegial de Xàtiva, su localidad natal. Aunque he revisado exhaustivamente los libros de Actas Capitulares de la Colegial de Xàtiva entre los años 1795 y 1815, no he encontrado referencia que confirme que nuestro biografiado ejerciera como tenor en dicha capilla. Como apunta Manel García Company en su tesis sobre la música en Xàtiva en el siglo XVIII, la capilla de música gozaba de cierta independencia respecto del cabildo, sobre todo para la contratación de músicos; además, la sección de músicos seglares de voz e instrumento dependía directamente de la ciudad, por lo cual, sólo se consignaba en las actas capitulares cuestiones relativas a cargos eclesiásticos (García, 2015, pp. 74-82). La admisión de un músico seglar necesitaba únicamente el voto favorable del resto de miembros de la capilla, pero toda la estructura solía supeditarse a las decisiones del maestro de ésta, que durante esta época era Josef Morata $(* 1769 ; \nmid 1840)^{38}$, por lo tanto, Acuña Castells podría haber sido contratado como asalariado de la ciudad.

La capilla adolecía de falta de voces «gruesas» y esta carencia se manifestaba frecuentemente en las reuniones capitulares ${ }^{39}$. En relación con esto, he podido documentar en 1808 una propuesta al cabildo — efectuada ya hacía algún tiempo — para admitir dos sujetos — cuyos nombres no trascendieron - procedentes de la colegial de San Nicolás en Alicante, uno de ellos con vOz gruesa para sochantre y el otro «tenor, músico, y toque de instrumento», cuyo perfil encajaría exactamente con las habilidades de Acuña, músico seglar, tenor con capacidad de cantar también como bajo, que sabía tocar el piano y la guitarra (véase el Diario de V alencia, núm. 29, 29.07.1810, p. 116). El cabildo autorizó a que, o bien el maestro de capilla, Josef Morata, o el Evangelistero ${ }^{40}$, que conocían a los cantantes procedentes de Alicante, les

\footnotetext{
${ }^{38}$ Josef Morata García (*Geldo, Segorbe, 1769; Valencia, 1840) fue maestro de capilla en la catedral de Segorbe desde 1786, de Xàtiva desde 1792 a 1814 y de la iglesia del colegio del Corpus Christi de Valencia desde 1829 hasta su muerte en 1840 (Capdepón, 1998; Pérez Giménez \& Pérez Giménez, 2009).

${ }^{39}$ En 1800 se convocaron oposiciones para cubrir una plaza de voz baja y otra para segundo organista. No se presentó nadie para la plaza de voz, pero Joseph Alberola, que fue el único en presentarse para tañer el órgano obtuvo dicha plaza tras superar un examen supervisado por Tomás Ciurana, entonces primer organista. Entre 1804 y 1805 figuran unos memoriales presentados por Bernardo Ribera, Ysidro Antolí y Bernardo Fárbega (Fábrega), entre otros, que aportan nuevos datos. Un apunte realizado en Julio confirma el mal estado de las rentas y alude a la adopción de un plan de reducción de beneficios; también reitera la necesidad de voces gruesas para el canto, por lo que solicita al señor arzobispo dos plazas más de salmista reservadas a eclesiásticos $(\boldsymbol{E}$ XAT: Actas Capitulares del año 1804, fol. 476 [25.06.1804]). En 1806 figura Josef Pastor como cantante de la citada capilla (Ibid., fol. 642 [01.08.1806]) junto al músico Bernardo Ribera y el músico de voz Francisco Mollá (Ibid., fol. 666 [07.01.1807]) y se referencian cuáles eran los músicos de voz de la capilla en dicha época (Ibid., fol. 674 [10.04.1807]) Cualquier ayuda era bienvenida dada la carestía económica vigente, por ello, en 1804, el estudiante Pedro Ferrando solicitó entrar en el coro para ejercitar la voz siéndole asignados hábitos talares para ello (1804, 555n). En 1811 se realizaron unas oposiciones a voz que ganaron Josef Perales, como sochantre, y Andrés Polomar, como capíscol de Andilla, segundo y ayudante de oficios (Ibid., fol. 103 [01.07.1811]); pero, aun así, seguían faltando voces gruesas en el coro (Ibid., fols. 103-104 [03.07.1811]). La muerte del epistolero Juan Peralta se suplió interinamente con $\mathrm{M}^{\mathrm{n}}$ Josef Ferrer y se solucionó parcialmente la escasez de voces con la admisión extraordinaria del exreligioso franciscano Ramón Boscadá y la incorporación de otro cantor oriundo de Albaida procedente de la capilla del Corpus Christi de Valencia (Ibid., fol. 199 [07.03.1812]).

40 Vicente Juan (en 1806) o Juan Peralta (en 1810).
} 


\section{JOSÉ GABRIEL GUAITA GABALDÓN}

hiciesen llegar la propuesta ${ }^{41}$. En esa misma época Acuña ya no trabajaba en las compañías de teatro de la capital, aunque había participado en los cuatro conciertos instrumentales celebrados en Madrid en marzo de 1808. Asimismo, tanto en Alicante como en Xàtiva, nuestro biografiado habría sido bien recibido por pertenecer a la familia de los Acuña, muy conocida en ambas ciudades — como va dicho, Fernando Acuña Faxardo fue organista en Xàtiva y Alicante; Juan Acuña Escarche, comenzó como infantillo en Xàtiva, y opositó después para ser organista en dicha capilla, mientras que su hermano Joaquín había sido acólito y también pretendiente a organista en dicha ciudad-.

Acuña Castells recaló en Valencia en el verano de 1810. En caso de proceder de las colegiales de Alicante o Xàtiva directamente, podría haberlo hecho buscando solaz veraniego; pero, si provenía de Madrid o provincias, seguramente huiría de la zona ocupada por los franceses ${ }^{42}$; también pudo influir la muerte de su tío, Joaquín Acuña Escarche, el 9 de septiembre de 1809. Lo cierto es que el 26 de julio de 1810, en pleno fragor de la ofensiva francesa, se celebró una velada musical protagonizada por Acuña en la capital del Turia, anunciada un día antes en el Diario de Valencia, en la que participó una orquesta. Cabe especificar que, durante todo este período, el término orquesta se aplicaba a formaciones de distinto tamaño y número, desde grupos de cámara a agrupaciones musicales instrumentales más amplias. Por ejemplo, el contrato de arriendo del teatro interino de Valencia para el año 1805, conocido como la Botiga de la Balda, comportaba la obligación de tener una «orquesta de los mejores músicos que puedan encontrarse, compuesta a lo menos de quatro violines, dos obueses, dos trompas, violinchelo y contrabajo» ${ }^{43}$, similar a la del teatro de Valladolid cuando trabajó Acuña, que constaba de cinco violines, dos violas, dos bajos, dos trompas y dos oboes (Alonso, 1921, p. 233).

Tal como detalla el anuncio del citado concierto celebrado el 26.07.1810, transcrito a continuación, Acuña interpretó diversas piezas de canto —acompañándose al piano- y un concierto nuevo para piano cuyo autor no se concreta:

\section{AVISOS}

El joven Acuña, Profesor de Música, natural de este Reyno, ofrece al Público un Concierto, con el permiso del Gobierno, en el que procurará reunir, tanto en la parte cantante como en la instrumental, lo más digno y agradable.

El Público sensible á las producciones de las artes y de la armonía, ha hecho justicia á los Extrangeros que han llamado su atención por un solo concierto instrumental o vocal; y esta sencilla prueba de su aprecio por quanto es capaz de embellecer su ilustración y su gusto, han estimulado á este Compatricio a presentarle reunidas estas dos qualidades músicas. El Concierto se dividirá en dos partes: la primera dará principio con una excelente Obertura; concluida esta, el Señor Acuña cantará un Rondó, composición del

\footnotetext{
${ }^{41}$ La capilla de la colegial de Alicante tenía en esta época un tenor titular, mosén Joseph Juan, que se hizo cargo interinamente del magisterio de dicha capilla en 1805 y añadió un segundo tenor y contralto al segundo coro. E-XAT: Actas Capitulares, fol. 734 [20.09.1808]

42 En 1812, huyendo de la ocupación francesa de Valencia, Acuña marcho a Palma de Mallorca, como otros muchos.

$43 \boldsymbol{E}$-VA Archivo General y Fotográfico de la Diputación de Valencia: correspondencia, VIII-3/C-1 legajos 6b-13.
} 
célebre Maestro Cimarosa: y finalizado este, tocará un gran Concierto nuevo obligado de piano-forte, en el que los Señores Profesores y aficionados verán reunidos el buen gusto moderno y las dificultades.

La segunda parte principiará por una grande Aria, composición del Señor Cimarosa: seguirá una Sinfonía nueva a toda orquesta: cantará dicho Señor Acuña una graciosa Canción con acompañamiento obligado de pianoforte: tocará un Tema con Variaciones de dicho instrumento; y finalizará el todo de la función con una Polaca graciosa.

La función se hará mañana día 26 en la casa núm. 25 de la plaza de Pellicers ${ }^{44}$, en donde se hallarán dicho día los boletines de asientos, a 10 reales de vellón, desde las nueve de la mañana. Se dará principio a las ocho y media de la noche en punto (Diario de V alencia, núm. 25, 25.07.1810, p. 100).

El concierto agradó al público, repitiéndose con repertorio ampliado el domingo 29 de julio en estos términos:

La acogida que ha tenido el profesor D. Josef Francisco Acuña en el primer Concierto instrumental y vocal, de la benignidad y gusto de la concurrencia que se dignó honrarle, le inspira la confianza de ofrecer una segunda función hoy Domingo, en la qual procurará reunir con la novedad de todas las piezas que execute, el gusto en la armonía, en la invención, y en el género de música. El piano-forte, como el conjunto del arte, merecerá su particular cuidado, y en la parte cantante empleará igualmente quanto crea capaz de interesar y mover. Nada omitirá para llenar las atenciones de un Público, cuya delicadeza y tino ha penetrado este Profesor en su primera y feliz tentativa. La ambición de agradar y perfeccionarse, que es la noble pasión de un artista, se mirará completamente satisfecha con la continuación de una benevolencia, que reclama todo su esmero y toda su gratitud.

La primera parte de la función dará principio con una Sinfonía; dicho Profesor cantará un Rondó de la ópera del Avaro: concluido, cantará una graciosa Canción en español con acompañamiento de piano-forte, titulada El Canario viajante, composición suya, y por final de esta primera parte tocará un gran concierto obligado de dicho instrumento, composición del señor Hoffmeiste (sic.) cuya obra es digna de la recomendación de todo buen Profesor.

Después de un corto descanso, dará principio la segunda parte por una grande Aria en español del Oratorio de el Saúl, tocará una Obertura; cantará varios juguetes a la guitarra y al piano; tocará una Sinfonía sólo con dicho instrumento; cantará un Dúo, en el que imitará con la mayor perfección la voz de baxo y tiple, de modo que parecerá estar cantando dos personas, cuya operación es muy difícil de executar por la contraposición de las voces, y finalizará el todo de la función con una Sinfonía.

El despacho de billetes estará abierto desde las 9 de la mañana, á 10 rs. vn. la entrada y silla (Diario de Valencia, núm. 29, 29.07.1810, p. 116). ${ }^{44}$ Dicha plaza se encontraba cerca al lado de la calle del Fumeral, enfrente de la casa Gremio de los Cortantes.
En los años 40 del s. XX desapareció por el trazado de la Avenida del Oeste. 


\section{JOSÉ GABRIEL GUAITA GABALDÓN}

Los dos conciertos, tal como evidencia su publicidad y contrariamente a la costumbre, estuvieron centrados únicamente en la persona de Acuña, que no compartió protagonismo con otros cantantes o pianistas, salvo con la orquesta que ejecutó las oberturas o sinfonías y el acompañamiento de las arias. La versatilidad en el canto y el piano le permitió ofrecer una función variada al gusto del público de la época en la cual el propio Acuña se acompañó al pianoforte. En cuanto a las obras interpretadas, el aria anunciada procede, posiblemente, de la ópera bufa l'Avaro de Valentino Fioravanti $(* 1764 ;$ †1837) estrenada en Nápoles en 1800 , o quizá de una pequeña y poco conocida ópera bufa de Francesco Bianchi, que fue estrenada en el Théatre des Italiens de París el 30.03.1804. La otra «en español del Oratorio el Saul» se corresponde con un oratorio contemporáneo homónimo compuesto en 1805 por Stefano Cristiani $(* 1770 ; \nmid 1825)$ del cual existe texto en castellano ${ }^{45}$ traducido por el poeta y periodista español Francisco Sánchez Barbero $\left({ }^{*} 1764 ; \nmid 1819\right)^{46}$ y fue estrenado el seis de marzo de 1805 en el teatro de los Caños del Peral con Manuel García como primer cantante ${ }^{47}$ (Radomski, 2000, p. 64). Obtuvo tal éxito, que la partitura ya se anunciaba a la venta arreglada para piano en la capital dos meses y medio después de su estreno (Gažta de Madrid, núm. 42, 24.05.1805, p. 455).

En cuanto a las obras para piano y orquesta ejecutadas en los recitales, resulta difícil discernir si ambos anuncios (Diario de Valencia, núm. 25, 25.07.1810, p. 100; núm. 29, 29.07 .1810 , p. 116) aluden a una misma obra o se trata de dos conciertos diferentes. El texto «concierto nuevo obligado para pianoforte» y la frase que le sigue «en el que los Señores Profesores y aficionados verán reunidos el buen gusto moderno y las dificultades», parece que indican el estreno de una composición del propio Acuña, la cual, posiblemente, además de en Valencia, también fue la interpretada en Madrid los días 8 y 9 de marzo de 1808; sin embargo, lamentablemente no se ha conservado su partitura. El segundo fue compuesto por el autor y editor alemán Franz Anton Hoffmeister — escrito «Hoffmeiste» en el anuncio(*1754; †1812), que aún vivía en aquella fecha ${ }^{48}$, por tanto, su temprana recepción en Valencia revela el alto grado de actualización que alcanzaba la actividad musical local ya por aquel entonces.

Josef Francisco Acuña también había comenzado por aquellas fechas a trabajar como arreglista de canciones patrióticas en la valenciana librería de Mallén de la calle de San Vicente, frente a la iglesia de San Martín, aunque su nombre no apareciera anuncios hasta después de realizados los dos conciertos mencionados. En el primer anuncio de partituras publicado por el Diario de Valencia, dicha librería ofrecía «una graciosa canción de guerra dedicada al excmo. Señor Marqués

\footnotetext{
$45 \boldsymbol{E}$-Mmb: sig. Mus 322-1; Mus 323.

46 El Saúl de Cristiani estaba basado en la tragedia Saul, de Vitorio Alfieri (*1749; †1803), estrenada en Siena en 1783 (Domínguez, 2006, p. 35).

${ }^{47}$ Se anunció así: «A las 8 de la noche se representará el drama sacro original, en a actos, nuevo, titulado: Saúl, puesto en música por D. Esteban Christiani. Actores en el drama: Sras. María López. Sres. Manuel García, Vicente García, Eusebio Fernandez y Juan Pau» (Diario de Madrid, núm. 65, 06.03.1805, p. 264). Una extensa carta publicada por el Diario ensalza la música de Cristiani y las actuaciones de Manuel García y la sra. López. También muestra la oposición de una parte del público del citado teatro hacia el autor, pues acusaba a Cristiani de falta de originalidad y de imitar, cuando no copiar, a «diferentes autores clásicos» (Diario de Madrid, núms. 87 y 89-92, 28, 30, 31.03.1805; 01 y 02.04.1805, pp. 349-372).

48 Aunque su catálogo todavía está incompleto, se sabe que compuso 14 conciertos para teclado (Weinmann, 2001).
} 


\section{NUEVos DATOS SOBRE LA SAGA MUSICAL DE LOS ACUÑA: EL CANTANTE, PIANISTA Y COPISTA JOSEF FRANCISCO ACUÑA Y CASTELLS (*XÀTIVA, 1778)}

de la Romana con su acompañamiento de guitarra», a 10 rs. vn. cada ejemplar ${ }^{49}$, y El Laurel de V alencia, himno patriótico con acompañamiento de pianoforte, que se vendía a $8 \mathrm{rs}$. $\mathrm{vn}^{50}$. Junto a estas piezas, se anunciaban unas «fáciles y graciosas boleras, con acompañamiento de guitarra, a 8 rv» y se especificaba un nuevo servicio de arreglos de partituras para piano a guitarra y viceversa -sin especificar quien se encargaría de efectuarlos- con el siguiente texto: «se advierte que todas las canciones, boleras, $\delta$ c que se publiquen con acompañamiento de guitarra se pondrán para piano, y las de este para guitarra, mediante encargo particular» (Diario de Valencia, núm. 73, 12.06.1810, p. 292); sin embargo, dado que es Acuña Castells quien aparece como arreglista en propagandas posteriores de dicha librería, es probable que también fuera él quien los realizara ya desde 1810 (véase Guaita, 2020).

El éxito alcanzado por los dos recitales efectuados por nuestro biografiado en Valencia aseguró los pedidos de la librería y dotó al copista de cierta notoriedad. A partir de aquel momento comenzó a constar su nombre como compositor y autor de los arreglos para pianoforte y guitarra en los anuncios de dicho establecimiento. Así pues, a los dos himnos patrióticos y las boleras del primer anuncio se les sumaron varias canciones líricas: El Canario viajante («una graciosa arieta, con acompañamiento de pianoforte» (Diario de Valencia, núm. 91, 29.09.1810, p. 364); una Canción nueva, con acompañamiento de pianoforte y de guitarra (Diario de V alencia, núm. 9, 09.10.1810, p. 36); y ElQuiero morir, canción con acompañamiento de guitarra (a 8 rs. vn.) o pianoforte (12 rs. vn.) (Diario de Valencia, núm. 34, 03.11.1810, p. 136). Acuña compuso, asimismo, música instrumental: Doce variaciones para fortepiano, flauta y baxo, sobre el tema de la canción bien conocida, que empieza: Dulce embeleso mio, \&\%. (Diario de Valencia, núm. 68, 26.09.1810, p. 352) $)^{51}$ — que se agotaron, debiendo preparar a toda prisa más copias— y el «vals para pianoforte» Las campanas de Londres (Diario de Valencia, 19.12.1810).

Como resultado de esta investigación, he podido localizar y documentar gracias a la inestimable ayuda del personal de la Otto Richter Library, en la Universidad de Miami, dos canciones líricas de Acuña, El Canario Viajante ${ }^{52}$ y El Amor, en una colección recopilatoria conocida como Lady Clive Harriet Collection, consistente en un cuaderno titulado Spanish Songs, con acompañamiento de fortepiano, que fue propiedad de Harriet Windsor-Clive (Alonso, 1998, p. 44) ${ }^{53}$.

Con respecto a la primera, para la creación de piececita de influencia italianizante y clásica, Acuña se valió de la utilización libre de la letra de una de las famosas fábulas de Tomás de Iriarte: El Canario y otros animales. Esta fábula se valía de una combinación poco usual de versos de arte menor, definida por el filólogo polímata Eduardo Benot (1892, vol.

\footnotetext{
${ }^{49}$ Louis Viardot — marido de Pauline, hija de Manuel García — habla explícitamente de la multiautoría en la composición de este tipo de piezas al afirmar que «En la calle se compone mucha música y muchas canciones populares; uno empieza, otro continua y un tercero concluye. Así es, por ejemplo, como se ha compuesto la bella canción patriótica del Marqués de la Romana» (Viardot, 1841, p. 240).

${ }^{50}$ Estas dos piezas acompañadas de unas Fáciles y graciosas boleras, con acompañamiento de guitarra, a 8 rs. vn.

${ }^{51}$ Agotadas las copias de esta obra, su venta se reanudó en noviembre (Diario de V alencia, núm. 88, 26.09.1810, p. 352).

52 Anunciada en la prensa como «graciosa arieta» con acompañamiento de pianoforte para la citada librería de Mallén (Diario de Valencia, núm. 91, 29.09.1810, p. 364).

${ }^{53}$ Harriet Windsor-Clive $(* 1797$; 1869$)$ fue una terrateniente y filántropa inglesa, esposa de Robert Henry Clive, barón de Windsor.
} 


\section{JosÉ GABRIEL GUAITA GABALDÓN}

3: 372-373) como «hexasílabos con consonantes cruzados i del mismo asonante ao todos los versos pares». La música de la pieza (allegretto, 3/8, sol mayor) consta de una introducción instrumental temática de 23 compases con octavas quebradas en la mano derecha y bajos tipo Alberti y Murky en el acompañamiento de la izquierda que sirve como pequeño interludio entre estrofas. Las armonías y construcción melódicas son simples e ingenuas, con la utilización de los acordes de tónica, subdominante y dominante, con algunos giros propios de la música popular andaluza (figura 6).

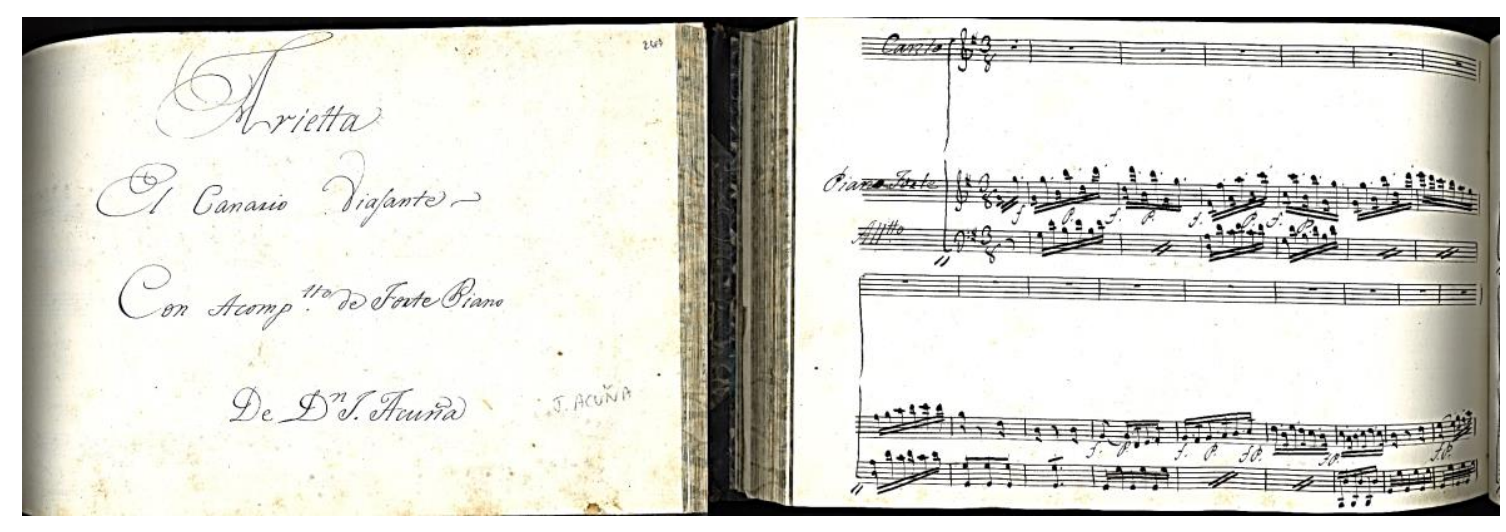

Fig. 6. José Acuña. El Canario Viajante. Lady Clive Harriet Collection (ASM 0240).

Respecto a El Amor, canción con acompañamiento de Piano-Forte del Señor Acuña (figura 7), es probable que se corresponda con la «canción nueva con acompañamiento de pianoforte y de guitarra» que se había anunciado en octubre de 1810 desde la librería de Mallén. Esta pieza (Andantino Allegretto, 6/8, sol mayor) muestra la claridad textural y sencillez armónica de otras canciones del periodo, con un acompañamiento arpegiado en la mano izquierda del piano y la línea melódica de la voz en la mano derecha. Posee una letra no identificada con ningún poema publicado de la época, por lo que probablemente fuera obra de algún escritor valenciano:

[1 $1^{a}$ letra] «Como es Amor niño | de todo recela | todo le da pena | angustia y dolor || teme y desconfía | se agita y padece | no creo merece | no creo merece | no creo merece | tal pago mi amor | tal pago mi amon»

[2 $2^{\mathrm{a}}$ letra] «Si en amarte fundo | yo la dicha mía $\mid$ por qué noche y día | sientes con rigor? || y en tanta constancia | cual mi fe te ofrece | no creo merece | no creo merece | no creo merece | tal pago mi amor | tal pago mi amor».

[ $3^{\mathrm{a}}$ letra] «consuela mi pecho $\mid$ con cariño amante $\mid \mathrm{q}^{\mathrm{e}}$ siempre constante $\mid$ y fiel te seré || No quieras qe muera $\mid$ de fiero dolor $\mid$ pues que no merece $\mid$ no creo merece | no creo merece | tal pago mi amor | tal pago mi amon». 


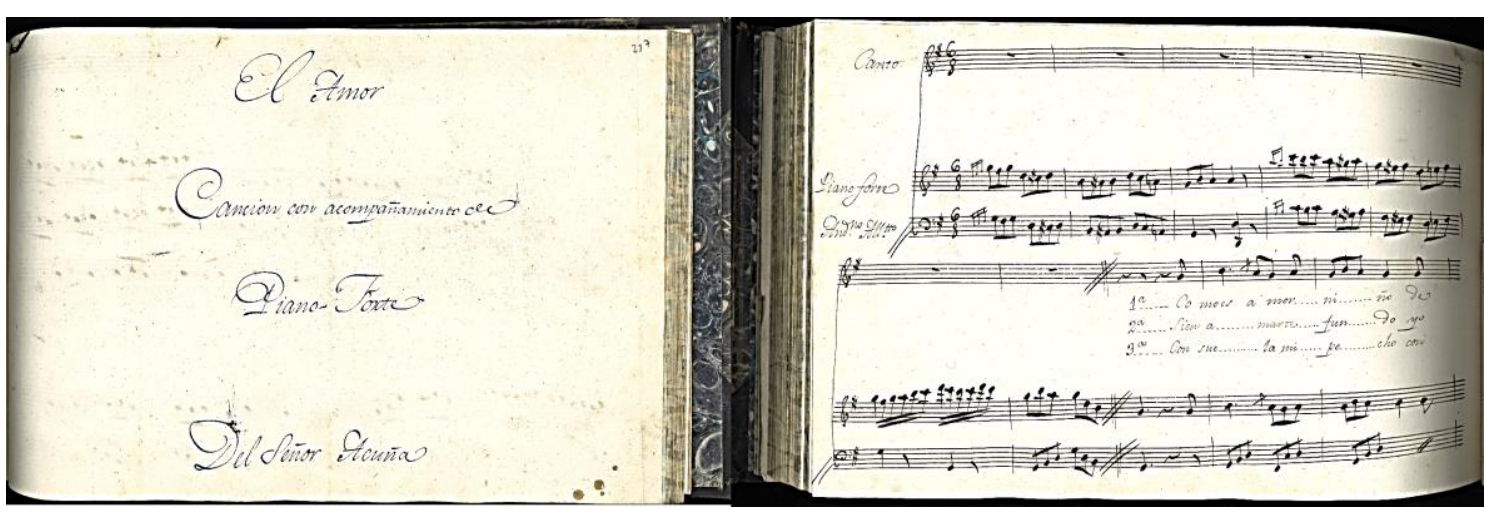

Fig. 7. José Acuña. El Amor. Lady Clive Harriet Collection (ASM 0240).

A partir de 1811, año de estrecheces para la ciudad de Valencia — debidas al desgaste producido por la proximidad del ejército francés- Mallén dejó de publicitar partituras y arreglos. A pesar de ello, las librerías de Salvador Faulí, en la plaza del colegio del Corpus Christi (del Patriarca) y la de su hijo Jayme Faulí (calle del Mar frente al convento de Sta. Tecla) aún ofrecieron algunas canciones entre finales de diciembre de 1810 y enero de 1811, entre las cuales destaca Fuego y Sangre, marcha española con acompañamiento de guitarra ${ }^{54}$, que había sido compuesta y publicitada en su versión con acompañamiento para piano ya en 1808 en Madrid por el propio Acuña. También he recuperado de $\boldsymbol{E}-M n$ una versión manuscrita de esta marcha (figura 8) firmada por nuestro biografiado y arreglada para coro de hombres y piano, la cual está titulada como Marcha Patriotica que se canta en el Exercito Nacional Del Reyno de Valencia. Puesta en musica y con Acomp to de Piano Forte por $D^{\prime \prime}$ Josef Fran ${ }^{\text {to }}$. Acuña ${ }^{55}$, comenzando con los mismos versos «Fuego y sangre, españoles» (Guaita, 2020, p. 217).

El ejemplar consultado, conservado en la Biblioteca Nacional de España, presenta deterioro por oxidación de la tinta en el soporte (pp.1-8). A la partitura para coro de hombres y piano original en formato italiano (apaisado) se le añadieron posteriormente hojas en vertical sin pautar en las que figura como título genérico Marcha Patriótica y, a continuación, el texto de la canción ordenada por estrofas. La música consta de una «Obertura marcial» instrumental en la tonalidad de Sol Mayor con indicaciones de efecto de clarines, caja, bombo y clarinete a modo de fanfarria militar —al estilo de las «batallas musicales» de Marengo (Bernard Viguerie) o Austerliz.(LouisEmmanuel Jadin) — de escritura más bien pobre, que introduce la marcha propiamente dicha. A la marcha le sigue un contrastante $\mathrm{Vals} \mathrm{All}^{\circ}$ [Allegro] en el característico compás ternario (3/8) de las canciones patrióticas de la época, que pone fin a la pieza.

\footnotetext{
${ }^{54}$ Fuego y Sangre, marcha española con acompañamiento de guitarra en la de Salvador Faulí y las ya anunciadas Canción Fúnebre del 2 de Mayo y la Marcha a los Patriotas extremeños en la de Jaime Faulí (Diario de Valencia, núm. 1, 07.01.1811, p. 28).

${ }_{55}^{5}$ El manuscrito se conserva en la Biblioteca Nacional de España y pertenece a la colección Gómez Imaz adquirida en subasta a Saskia-Sotheby's en Madrid el 17 de mayo de 1977. E-Mn: R/62517.
} 


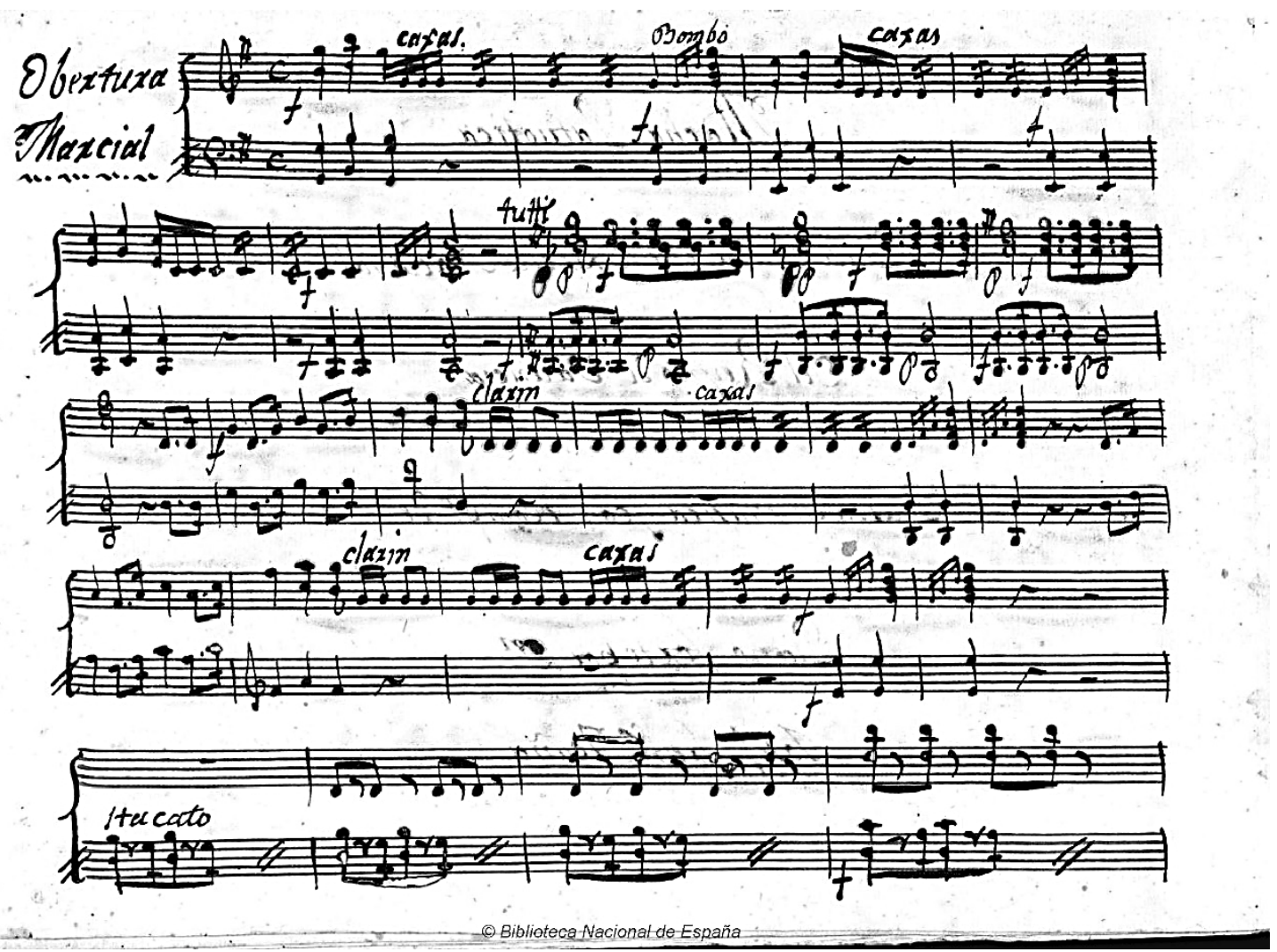

Fig. 8. Primera página de la Marcha Patriotica que se canta en el Exercito Nacional Del Reyno de Valencia.

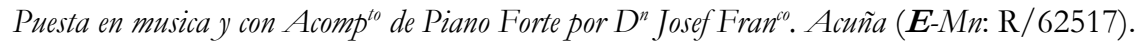

\section{Estancia en Palma de MallorCa (1812-1813).}

Aunque, como va dicho, Josef Acuña apareció como «nuevo» integrante de la compañía cómica del teatro del Príncipe para la temporada 1812-1813, no se presentó a ella. José Joaquín Esteve documenta hemerográficamente ${ }^{56}$ en su tesis (2016) que Acuña se trasladó a Palma de Mallorca durante el primer semestre del año 1812. Es más, el texto de uno de los anuncios, aparecido en mayo, ofrece los servicios del cantante como maestro de música:

\footnotetext{
Se halla en esta ciudad el profesor de música D. Josef Acuña y Castelli ${ }^{57}$, tenor de la iglesia colegial de Xátiva en el Reyno de Valencia: los elogios que ha merecido este artista en los papeles públicos de las principales capitales de España por donde a viajado dando conciertos, dan fundados motivos para no dudar de su mérito: la persona que guste recibirle por maestro dexará razón en la librería de Miguel Domingo, calle de la Capelería. Nota: dará lección gratis en su propia casa á los hijos de padres pobres que teniendo disposición para aprender quieran seguir la carrera de la música (Diario de Palma, núm. 150, 29.05.1812, p. 644, cit. en Esteve Vaquer, 2016, IV, p. 70).
}

\footnotetext{
${ }^{56}$ He podido comprobar cómo nueve días antes, alguien que no dio señas de identidad, demandaba en el diario la dirección de «el Sr. Acuña, músico de profesión» (Diario de Mallorca, núm. 143, 20.05.1812, p. 578).

${ }^{57}$ Aquí se produce una confusión ortográfica con su segundo apellido, Castells.
} 


\section{NUEVOS DATOS SOBRE LA SAGA MUSICAL DE LOS ACUÑA: EL CANTANTE, PIANISTA Y COPISTA JOSEF FRANCISCO ACUÑA Y CASTELLS (*XÀTIVA, 1778)}

Asimismo, he podido comprobar que insertó el mismo texto, con ligeros cambios, en el Diario de Mallorca:

\section{Noticias del Pais.}

Se halla en esta Ciudad, el profesor de música D. José Acuña y Castelli, tenor de la Iglesia Colegial de Xativa, en el Reyno de Valencia: los elogios que se han hecho de este artista en los papeles públicos de las principales capitales de España, dando conciertos, dan fundados motivos para no dudar de su mérito: la persona que guste recibirle por maestro acudirá à la librería de Miguel Domingo calle de la Capallería [Capelleria], quien dará razón. Asimismo advierte que dará lección gratis en su casa á los hijos de padres pobres, que teniendo disposición para aprender quieran seguir la carrera de la música (Diario de Mallorca, núm. 155, 29.07.1812, p. 613).

El librero Miguel Domingo, que le hospedaba y ejercía como protector de Acuña en la isla, había emigrado de Valencia ${ }^{58}$ con toda su familia entre 1810 y 1811, bien huyendo de la dominación francesa, bien como acicate ideológico de la causa liberal, tratando de infiltrarse en la reaccionaria sociedad mallorquina (Oliver, 1901, pp. 490-491) ${ }^{59}$. En Valencia había tenido problemas con el Santo Oficio, pues fue acusado de vender libros prohibidos. Durante el proceso se reveló que Domingo los obtenía en la librería de Pedro Juan Mallén ${ }^{60}$, donde trabajaba Acuña como copista ${ }^{61}$. Una vez en Palma, sus inclinaciones liberales llevaron a Domingo a asociarse con Isidoro de Antillón en la creación de un periódico nuevo: la Aurora Patriótica Mallorquina, del que Domingo era impresor y editor y Antillón redactor jefe. Su librería y la de Nicolás Carbonell, que fueron verdaderos centros ideológicos y propagandísticos del sector liberal en la sociedad insular, protagonizaron numerosas polémicas (Rodríguez, 2012, p. 169).

La llegada de Acuña a la Mallorca también causó cierta polémica, ya que, en el primer fin de semana de julio - días cuatro y cinco de ese mes-, se celebraron sendos conciertos a beneficio de los presos necesitados en los que participó cantando, entre otras piezas, varias arias y un himno patriótico nacional ${ }^{62}$ - probablemente uno de los dos que había compuesto y comercializado en Valencia a finales de $1810^{63}$ - No pudo ofrecer obras nuevas en el segundo concierto, dado que se realizaron en días consecutivos ${ }^{64}$, tal y como se había anunciado, lo

\footnotetext{
${ }^{58}$ Donde había comerciado con libros nuevos y viejos desde 1805 (Serrano, 1899, p. 122).

${ }^{59}$ Felipe Rodríguez $(2012,2013)$ ha estudiado exhaustivamente la vida, influencia y repercusión que tuvo Miguel Domingo en Palma de Mallorca.

${ }^{60} \boldsymbol{E}$-Mah: Inquisición, 3732-316: fol. 2v (cit. en Rodríguez, 2013, p. 367).

${ }^{61}$ De hecho, Mallén era conocido por publicar en secreto obras prohibidas (Bas, 2013, p. 193).

${ }^{62}$ Han podido conocerse las obras interpretadas gracias a la información que figura en prensa en prensa [véase tabla 1].

${ }^{63}$ El laurel de V alencia, o Fuego y sangre, marcha española.

${ }^{64}$ Estos recitales fueron organizados por José Veleña, juez de la Real Audiencia (Diario de Mallorca, núm. 110, 10.07.1812, p. 774), y, aunque Esteve (2016) no lo menciona, se celebraron en paralelo a otras representaciones dramáticas y festivas. El día 4 se representaron las obras Esquileo, Hércules y Deyanira, se bailó el fandango, y se representó la ópera de la Gitanilla fingida en el teatro (Diario de Mallorca, núm. 135, 04.07.1812, p. 744; Diario de Palma, núm. 86, 04.07.1812, p. 504). El día 5, a la vez que el segundo concierto de Acuña, tuvieron lugar una corrida de toros, una función de fuegos artificiales con dos castillos de fuegos de artificio y otros divertimentos pirotécnicos en la ciudad, cuya recaudación fue destinada por Maestreti, organizador de los eventos, también a
} 


\section{JOSÉ GABRIEL GUAITA GABALDÓN}

que indignó a parte del público. En la adversa crítica de A. J. publicada en el diario Aurora Patriótica Mallorquina, su autor confesaba que no había asistido a la segunda función por no haberle divertido la primera y censuraba que Acuña repitiera muchas piezas del día anterior. Criticaba, asimismo, el formato monográfico de concierto en el que actuaba un solo artista, poco frecuente en la época, y la falta de estilo de Acuña, que le pareció plano en cuanto a fraseo y matices, lo que, a su juicio, daba una imagen de excesiva sobriedad que llevaba al público a la distracción:

[...] el canto repetido de una voz sola por buena que sea (y en esta clase cuento la de vd.) es algo cansado quando no la acompañan las gracias de un estilo privilegiado, y de una sobria egecucion, porque quando esta se prodiga con exceso, y no se marcan bien los puntos capitales que el autor ha señalado y no debe olvidar el que canta, lejos de agradecerlo el auditorio que tenga oído, sentirá una profusion de puntos que le distrae de lo principal [...] (Aurora Patriótica Mallorquina, 08.07 .1812 cit. en Esteve, 2016, IV, pp. 72).

La crítica fue rápidamente respondida por M.G.C. - Miguel Domingo, editor del periódico- a través de un extenso artículo en el que defendía al cantante y ridiculizaba el criterio del detractor ${ }^{65}$. Para M.G.C., Acuña, a quien conocía desde hacía más de nueve años, «cantó y tocó mucho y muy bien» en los dos conciertos y aseveró que su continuo estudio le había hecho ser un adelantado en la profesión. Explicaba que, aunque repitió dos arias en el segundo concierto, las varió y adornó con «glosas mejor colocadas», repitiendo la ejecución de «juguetes y cancioncitas»a petición de las señoras del público. Del texto de Domingo se desprende, además, que no consiguió satisfacer a los críticos, lo que atribuye al hecho de no haber ejecutado música popular — un fandango ${ }^{66}$ - ni haber cantado la popular piu piu orsa nineta $^{67}$. Continaba elogiando las características sobresalientes de Acuña destacando que era capaz de cantar «monoteando o cromaticando» ${ }^{68}$, dado que poseía la inusual facultad de contar con «24 puntos de voz, entre bajo, tenor, alto i tiple», lo que demostró en el dúo que cantó a solo — probablemente el mismo que interpretó antes en Valencia—. Posiblemente se refería a que la tesitura total que Acuña comprendía en torno a tres octavas (veinticuatro notas), cuando habitualmente un tenor abarca sólo dos, por lo que podía abordar papeles de diversas tesituras vocales. Además, repitiendo lo consignado por la Gąeta de Valencia en 1810, reseñó un dato curioso: Acuña conocía los tonos [tonalidades] en los que se hallaba siempre mientras cantaba, dada la sólida formación que poseía en contrapunto y composición, y subrayó su

\footnotetext{
los presos. Simultáneamente, el teatro programaba exactamente las mismas obras que el día anterior (Diario de Palma, núm. 87, 05.07.1812, p. 508).

${ }_{65}$ Aunque las siglas parecen indicar otra persona, en otro anuncio se explicita que este defensor era «su amigo el editor de la Aurora», que no era otra que el librero e impresor Miguel Domingo (Diario de Mallorca, núm. 122, 22.07.1812, p. P. 825).

${ }^{66}$ Danza procedente del folklore que gozaba entonces de gran aceptación por parte del público y se bailaba como intermedio entre las comedias y óperas de los teatros.

${ }^{67}$ ¡Orsa nineta!, posa brosa al niu [jOrsa niñita!, pon broza al nido (figurado)] es un verso de un poema popular de temática erótica titulado El trapero catalán recopilado y musicado por Tomás Segarra, profesor de español y lector de la Universidad de Munich (1862, p. 295).

68 Domingo podría referirse quizá con esas expresiones a cuando Acuña cantaba una sola melodía (monoteando) o emitía él mismo dos voces diferentes simulando un dúo (cromaticando), o tal vez a la improvisación con modulaciones.
} 


\section{NUEVOS DATOS SOBRE LA SAGA MUSICAL DE LOS ACUÑA: EL CANTANTE, PIANISTA Y COPISTA JOSEF FRANCISCO ACUÑA Y CASTELLS (*XÀTIVA, 1778)}

facultad de dominar varios instrumentos. El texto finaliza con M.G.C. invitando al autor de la negativa crítica a acudir a un convite en su propia casa, donde el mismo Acuña le mostraría sus destrezas, accediendo a tocar y cantar todas las piezas difíciles que este le mostrase:

[...] El profesor de música don José Acuña, á quien conozco hace más de 10 años, cantó y tocó mucho y bien en los conciertos del sábado y domingo: sería demaciado molesto si patentizase á V. el adelantamiento que se le nota en su profesion, conseguida á fuerza de un continuo estudio; pero sí diré que aunque repitió dos arias en el $2^{\circ}$ concierto, fueron oídos por los inteligentes con mas gusto, por haberlas adornado con glosas bien colocadas, circunstancia en que estaba el mérito de un cantante; no quedando duda alguna que tantas quantas veces las repita, seguirá glosandolas hasta conseguir que V. como poco inteligente, no conozca si son las mismas. Si igualmente repitió los juguetes y las cancioncitas, fué porque algunas de las señoras, de oído mas delicado que el de su amigo de $\mathrm{V}$. conociendo lo agradable que eran, le instaron para que así lo hiciese: y ultimamente, si este profesor no llenó enteramente, las intenciones de V. y su amigo en el primero y segundo concierto, donde los verdaderos inteligentes, le oyeron tocar, y cantar con una desemboltura, y posesión nada comun, sería porque no executó, el fandango, ó la cancion de piu piu orsa nineta.

[...] Este apreciable compositor, ofrezco á V. cantará si gusta, sugeto á un compas monoteando, ó cromaticando, cuanto V. quiera; bien que estas voces ténicas en música, creo que le serán á V. desconocidas. Satisfecho de que puedo prometerlo, desearé (pues soy un regular aficionado) que en mi casa se junten vds. para cantar y tocar cuantas piezas difíciles pueda V. proporcionar; y por último, naturaleza le ha concedido 24 puntos de voz, entre bajo, tenor, alto y tiple; que demostró muy bien, el dúo que cantó á solo: como ha de ser, esto no estuvo á el alcance de V., paciencia. Don José Acuña, cuando canta, sabe en los tonos donde se halla, pues conoce á fondo el contra-punto, como dice la gazeta de Valencia del mártes 18 de setiembre de 1810. Reune á la composicion, la buena voz, el buen arte de cantar, destreza en música, y la parte práctica de poseer varios instrumentos [...] (Diario de Mallorca, núms. 110 y 111, 10 y 11.07.1812, pp. 774-775 y 780-781).

Acuña agradeció al día siguiente en prensa la defensa de su anfitrión en Palma y accedió a la oferta de asistir al convite propuesto. Se defendió incidiendo en los completos estudios que poseía y la total dedicación que había dispensado a la música desde su niñez, manifestando desprecio por la opinión de personas con poca formación musical que juzgan la interpretación artística de otros (Diario de Mallorca, núm. 112,12.07.1812, pp. 785-786). De hecho, difícilmente podría rehusarla, pues he podido constatar que su residencia —al menos seis meses después - aún estaba ubicada en la casa de Miguel Domingo de la plaza del Mercado, número 9, dado que esa era la dirección que daba a comienzos de 1813 cuando ofertaba partituras de canto:

Venta. Se vende una colección de arias, todas de Cimarosa, Paisiello y otros buenos autores: el profesor D. Josef Acuña, que vive en la plaza del Mercado, núm. 9, dará razón (Diario de Palma, núm. 134, 17.01.1813, p. 564). 


\section{JOSÉ GABRIEL GUAITA GABALDÓN}

En días posteriores se intentó rentabilizar la polémica poniendo a la venta como papel suelto en otra librería progresista mallorquina, la de Nicolás Carbonell (véase Rodríguez, 2013, p. 348), la carta en la que Acuña respondía a las críticas de A. J. a través del siguiente anuncio:

Noticias del país.

Hoy á las 10 de esta mañana, se hallará de venta en la librería de Carbonell, a 3 quartos, el papel suelto titulado: Carta del profesor de música D. José Acuña al cavallero criticador Don A. J., y contestación á la nota de su amigo el editor de la Aurora (Diario de Mallorca, núm. 122, 22.07.1812, p. 825).

Dos días después se anunciaron, desde la librería de su amigo Miguel Domingo, «frente a la cárcel [plaza de Cort]», varias obras «puestas en música por él mismo» que había cantado en los conciertos patrióticos y estaban dedicadas al general Whitingam y su brillante división: un himno, una marcha y un pasodoble militar; cada obra costaba 9 quartos (Diario de Mallorca, núm. 124, 24.07.1812, p. 834).

Concluyendo, Josef Acuña Castells utilizó su completa formación musical para desarrollar una provechosa faceta de copista que le sirvió como complemento pecuniario a la actividad artística que desarrolló en teatros y conciertos y al ejercicio de la docencia musical. Además de transcribir, copiar o arreglar músicas demandadas por la masa social, musicó acompañamientos para fortepiano y guitarra, instrumentos que dominaba — especialmente el fortepiano, dado el repertorio de alto nivel que interpretaba en sus conciertos-, y compuso obras específicas para el piano sobre las que, a pesar de que hoy todavía no han podido recuperarse, hay constancia hemerográfica de su existencia.

Con el fin de la guerra, los testimonios bibliográficos y hemerográficos sobre su persona desaparecen por completo. Su principal valedor en Mallorca, Miguel Domingo, fue desterrado por cuatro años a Ibiza por haber impreso panfletos y periódicos a favor de la constitución y la causa liberal —a pesar de que por entonces ya había regresado a Valencia-; también por vender libros considerados prohibidos y actuar, en general, como un agente liberal (Rodríguez, 2013, pp. 384 y ss.) ${ }^{69}$.

Resultaba verosímil relacionarlo con la figura de otro José Acuña, empresario teatral en Granada que aparece en varios documentos hacia la década de 1840, siendo empresario de la compañía dramática de Granada (véase Oliver, 2012, pp. 93-183; La Esperanza, periódico literario, núm. 14, 07.07.1839, p. 112; El Entreacto, periódico de teatros, literatura y artes, núm. 42, 22.08.1839, pp. 165-166), cuya trayectoria profesional encajaría con su trayectoria vital y la de sus correligionarios. Sin embargo, he de descartar totalmente la identificación de este Acuña con el personaje estudiado, ya que he podido comprobar mediante el cotejo de

\footnotetext{
${ }^{69}$ Más tarde consiguió abrir de nuevo la librería asociándose con su yerno, Ildefonso Mompié, en el número 48 de la calle Caballeros, manzana 373, como informa asimismo la matriculación vecinal de 1818. En su taller se editaron, durante el Trienio Liberal, la publicación política periódica El Amolador y el Diario Patriótico de la Ciudad de Valencia (Rodríguez, 2012, pp. 182-185). Véase E-VAa: Padrón de la ciudad de Valencia, sig. 4, 1818.
} 


\section{NUEVos DATOS SOBRE LA SAGA MUSICAL DE LOS ACUÑA: EL CANTANTE, PIANISTA}

Y COPISTA JOSEF FRANCISCO ACUÑA Y CASTELLS (*XàTIVA, 1778)

diversos registros de nacimiento de sus hijas e hijos que no se trata de la misma persona, sino que este último fue un escribano granadino con segundo apellido y ascendientes diferentes (José Acuña y Avelenda), el cual se reconvirtió en agente teatral, invirtiendo toda su fortuna en el teatro de Granada y arruinándose más tarde, tal y como manifestó su viuda, Dolores Romero Saavedra, a su muerte ${ }^{70}$.

$70 \boldsymbol{E}$-GR, Archivo Histórico Municipal de Granada (AHMGr): sig. C.00206.0022. Véanse, asimismo los diferentes registros de nacimientos de Granada en los que aparece José Acuña Avelenda y Dolores Romero Saavedra como progenitores, registrados y digitalizados por la empresa familysearch.org [consulta el 17.05.2021]. 


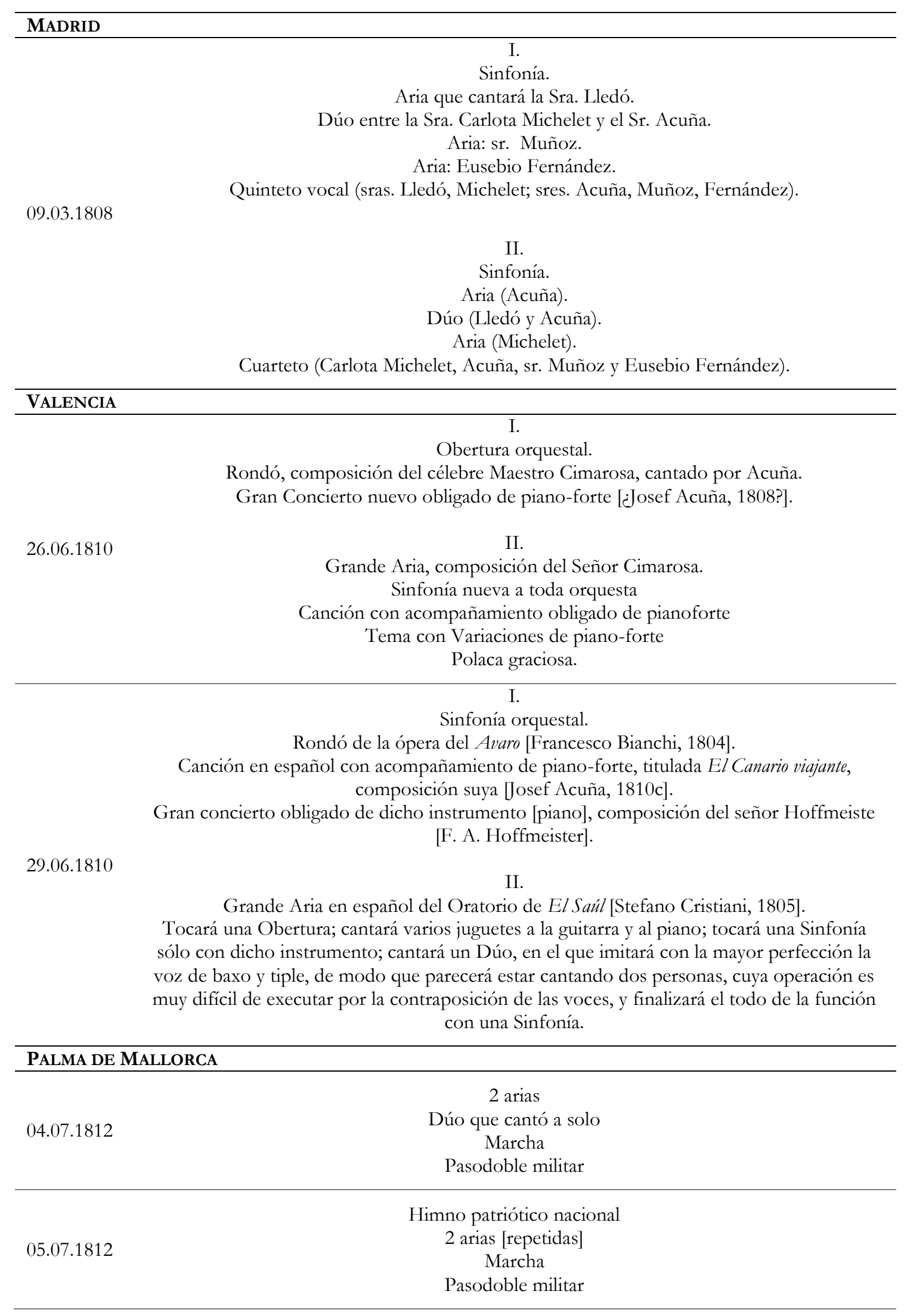

Tabla 1. Conciertos y repertorio de Josef Acuña (1808-1812).

(Elaboración propia). 
NUEVOS DATOS SOBRE LA SAGA MUSICAL DE LOS ACUÑA: EL CANTANTE, PIANISTA

Y COPISTA JOSEF FRANCISCO ACUÑA Y CASTELlS (*XàTIVA, 1778)

\section{Librería de MALlÉN, CALle SAN Vicente, VALENCia.}

Una graciosa canción de guerra dedicada al excmo. Señor Marqués de la Romana con su acompañamiento de guitarra a 10 rs. vn. cada ejemplar.

12.06.1810

El himno patriótico titulado el laurel de Valencia, con acompañamiento de pianoforte, a 10 rs.vn.

Fáciles y graciosas boleras, con acompañamiento de guitarra, a 8 rs.vn.

\begin{tabular}{l} 
26.09.1810 $\begin{array}{l}\text { Doce variaciones para fortepiano, flauta y baxo, sobre el tema de la canción bien conocida, que } \\
\text { empieza: dulce embeleso mio, Ec. compuestas por el señor Acuña. }\end{array}$ \\
$\begin{array}{l}\text { El Canario viajante. Graciosa arieta, con acompañamiento de pianoforte puesta en } \\
\text { música por el señor Acuña. }\end{array}$ \\
$\begin{array}{l}\text { Canción nueva, con acompañamiento de pianoforte y de guitarra, composición del } \\
\text { señor Acuña. }\end{array}$ \\
\hline $\begin{array}{l}\text { El quiero morir, canción con acompañamiento de guitarra, a } 8 \text { rs. vn. o pianoforte a } \\
12 \text { rs. vn.; Variaciones para piano, flauta y baxo, que se habían agotado [del anuncio } \\
\text { del } 26.09] .\end{array}$ \\
\hline
\end{tabular}

Vals para pianoforte: Las campanas de Londres.

19.12.1810 Himno patriótico: El laurel de Valencia y Canción dedicada al excelentísimo Señor Marqués de la Romana con acompañamiento de pianoforte y guitarra del señor Acuña.

Librería de SAlVAdor FAUlí, Plaza del COLEgio del CorPUS CHRISTI, VALENCIA.

Marcha española: Fuego y Sangre [Marcha patriótica que se canta en el ejército nacional del Reino
de V alencia].

Librería de Miguel Domingo, Calle de Capelleria, Palma de Mallorca.

\begin{tabular}{ll} 
& Himno. \\
24.07.1812 & Marcha. \\
& Pasodoble militar. \\
\hline
\end{tabular}

Plaza del Mercado, No 9 [Casa de M.G.C.], Palma de Mallorca.

17.01.1813 Colección de arias de Cimarosa, Paisiello, y otros.

Tabla 2. Anuncios de obras en venta compuestas o arregladas por Josef Acuña.

(Elaboración propia). 


\section{CONCLUSIONES}

La investigación que recoge este artículo ha permitido dar a conocer la destacable labor de un quinto miembro procedente de la ya documentada familia de músicos Acuña que, si bien rompió finalmente con la tradición musical religiosa de la familia, protagonizó una interesante trayectoria relacionada con la actividad musical.

Josef Francisco Acuña y Castells fue sobrino de los dieciochescos Juan y Joaquín Acuña y Escarche e hijo de un hermano de ambos, Fernando, que no se dedicó a la música. Lejos de tomar órdenes como sus tíos paternos, Josef Acuña nunca integró institución eclesiástica alguna — salvo durante el inespecífico período en el que fue tenor de la colegial de Xàtiva, y consiguió triunfar en los teatros de la corte, en los que actuó entre los veintidós y los treinta años aprovechando el auge de la música en las compañías españolas de principios de siglo — período previo a la irrupción del italianismo rossiniano en España—.

En 1810, el estallido de la Guerra de la Independencia hizo que dejara la capital y corte para instalarse, primero en la capital del Turia, donde había fallecido su tío en 1809, y, tras su caída en manos francesas, en Palma de Mallorca. Durante su estancia en Valencia mientras la capital sufría el segundo asedio galo (1810)—, consiguió mantenerse activo a pesar de la tensión social realizando dos conciertos y trabajando como compositor de canciones patrióticas y copista de partituras para distintas librerías de la ciudad, en una época de ferviente actividad y distribución de canciones patrióticas (Guaita, 2020). Al caer Valencia se refugió, como tantos otros, en Palma de Mallorca y, protegido por el librero Miguel Domingo, se integró en el círculo liberal y activista al que éste pertenecía, en una ciudad con profundas raíces realistas. Allí retomó sus conciertos y volvió a trabajar como arreglador, copista y compositor de himnos. Su rastro biográfico desaparece tras la guerra de la Independencia.

Cabe decir que la recuperación biográfica y profesional de una figura como la de Acuña ayuda a obtener una serie de conclusiones tangenciales que redundan en la justificación de este trabajo. Por un lado, al ofrecer una panorámica global de la historia vital y profesional de nuestro biografiado por primera vez, únicamente presente hasta ahora gracias a dispersas referencias bibliográficas y hemerográficas, se ahonda en el estudio de la música española en la primera mitad del siglo XIX, el contexto de reajustes de la ópera en España y, además, se contribuye a investigar la actividad teatral autóctona durante dicho período, previo a la Guerra de la Independencia, completando algunas lagunas historiográficas. Por otra parte, gracias al estudio y cotejo sistemático de fuentes hemerográficas y archivísticas, se ilustra la actividad uno de los principales tenores de la zarzuela y ópera española, el cual formó parte de las compañías de la corte que manejaba Isidoro Máiquez, de las que formaban parte el relevante tenor rossiniano Manuel García, las hermanas Correa y Joaquina Sitches, «la Briones». Ha resultado de gran interés, asimismo, confirmar unas notables características específicas de la voz de Acuña Castells que han sido constatadas en diferentes fuentes, pues abren la puerta a elaborar un estudio técnico que relacione el repertorio cantado por Acuña como tenor y bajo en teatros y conciertos, para tratar de explicarlas técnica y/o fisiológicamente. 


\section{NUEVos DATOS SOBRE LA SAGA MUSICAL DE LOS ACUÑA: EL CANTANTE, PIANISTA}

Y COPISTA JOSEF FRANCISCO ACUÑA Y CASTELLS (*XàTIVA, 1778)

Unido a ello, se pone nombre a uno de los primeros autores de canciones patrióticas y canciones líricas activo durante la Guerra de la Independencia en el levante español, que también trabajó en dicha época asociado a librerías valencianas como copista de partituras para piano y guitarra y viceversa. Por ello, se abre la puerta a un estudio sistemático para conseguir comprender el desarrollo y la evolución de la edición manuscrita y los modelos de transmisión de la música en la Valencia de principios de siglo, tema no abordado en profundidad hasta la fecha, así como investigar la función social que tuvo el uso de las diversas tipologías de canciones y cómo se asociaron las diferencias de instrumentación en los arreglos al precio de las obras y su uso por las distintas capas sociales urbanas.

No es menos importante la perspectiva que se abre con este trabajo a la recuperación del repertorio de Acuña, tanto de sus obras líricas y patrióticas como al manifestado en sus conciertos públicos a solo, dado que fue uno de los pioneros en realizar funciones variadas de música vocal e instrumental sin la intervención de otros artistas debido a su versatilidad con la voz y el piano.

Además, derivadas de este estudio se plantean algunas cuestiones no cerradas, las cuales pueden permitir seguir con una línea de investigación, tomando como punto de partida los datos aportados, que permita documentar el legado y posterior trayectoria de estos músicos polifacéticos menos conocidos, los cuales integraron las distintas compañías teatrales a comienzos de siglo, a través de los grandes cambios políticos, sociales y culturales que condujeron a la España contemporánea.

\section{BIBLIOGRAFÍA}

Aguilar, J. de D. (1983). La música en la provincia de Alicante. Alicante: Instituto de Estudios Alicantinos.

Alonso, C. (1998). La canción lírica española en el siglo XIX. Madrid: ICCMU.

Alonso, N. (1921). El teatro en Valladolid. Boletin de la Real Academia Española, VIII, cuaderno XXXVII, pp. 226-263.

Andioc, R. y M. Coullon (2008). Cartelera teatral madrileña del siglo XVIII (1708-1808). Madrid: Fundación Universitaria Española.

Andrés, M. A. (2015). Patrimoniosn: un proyecto de seducción entre la música y el territorio. Opción, año 31 (4, especial), pp. 1025-1035.

Arregui, J. P. (2009). Valladolid y el teatro ante la expectativa burguesa: contexto y proceso: aspiraciones, proyectos e iniciativas teatrales a mediados del siglo XIX. Universidad de Valladolid, Secretariado de Publicaciones e Intercambio Editorial. 


\section{JOSÉ GABRIEL GUAITA GABALDÓN}

Bas, N. (2013). Un soplo de aire fresco: libros franceses en los Catálogos del siglo XVIII de la librería Mallén de Valencia. Revista General de Información y Documentación, 23, pp. 173-200.

Bordas, C. (1988). Dos constructores de pianos en Madrid: Francisco Flórez y Francisco Fernández. Revista de Musicología, 11, 3, pp. 807-851.

Capdepón, P. (1998). La capilla de música de la catedral de Segorbe en el siglo XVIII. Anuario Musical, 53, pp. 191-224.

Capdepó, P. (1999). Soler y Ramos, A. En E. Casares Rodicio (Dir.), Diccionario de la Música Española e Hispanoamericana, vol. 9 (pp. 1128-1132). Madrid: SGAE.

Carmena, L. (1878). Crónica de la ópera italiana en Madrid desde el año 1738 hasta nuestros días. Madrid: Minuesa de los Ríos.

Carreras, J. J. (Ed.) (2018). Historia de la música en España e Hispanoamérica, vol. 5: la música en España en el siglo XIX. Madrid/México D.F.: Fondo de Cultura Económica.

Casares, E. (2018). Procesos de recepción y modelos de creación. Desde Carlos IV al periodo fernandino (1787-1833). Madrid: ICCMU.

Climent, J. (2002). Orguens $i$ organistes catedralicis de la Valencia del segle XIX. Valencia: Lo Rat Penat.

Cotarelo, E. (1899). Don Ramón de la Cruz y sus obras: ensayo biográfico y bibliográfico. Madrid: Perales y Martínez.

Cotarelo, E. (1902). Isidoro Maiquez y el teatro de su tiempo. Madrid: imp. de José Perales y Martínez.

Diana, M.J. (1850). Memoria histórico-artística del Teatro Real de Madrid. Madrid: Imprenta Nacional.

Díez, C. (2009). Teatro, canciones e himnos patrióticos: la música al servicio de los ideales políticos en el Cádiz de las Cortes, Cuadernos de Música Iberoamericana, 18, pp. 736.

Domínguez, J. M. (2006). Esteban Cristiani, un compositor italiano entre España e Hispanoamérica. Cuadernos de Música Iberoamericana, 12, pp. 5-38.

Esteve, J. J. (2016). Som pobres de solemnitat! Cap a l'emancipació del músic preromàntic a Palma de Mallorca. (Tesis Doctoral). Barcelona: Universitat Autónoma de Barcelona.

Fernández, E. (2009). Un compositor olvidado en el Madrid de Carlos IV: José María de los Reyes Francesconi y Suffó. Cuadernos de Música Iberoamericana, 17, pp. 23-60. 


\section{NUEVos DATOS SOBRE LA SAGA MUSICAL DE LOS ACUÑA: EL CANTANTE, PIANISTA}

Y COPISTA JOSEF FRANCISCO ACUÑA Y CASTELLS (*XàTIVA, 1778)

García, J. M. (2016). La música a Xàtiva durant el segle XVIII. (Tesis doctoral). Valencia: Universitat de València.

Guaita, J. G. (2020). La música patriótica en Valencia durante la Guerra de la Independencia Española (1808-1814): mercado y repertorio. Cuadernos de Música Iberoamericana, 33, pp. 199-224.

Llopis, E. y García, H. (2011). Precios y salarios en Madrid, 1680-1800. Investigaciones de Historia Económica, 7, pp. 295-309.

López de José, A. (2006). Los teatros cortesanos en el siglo XVIII: Aranjuezy San Ildefonso. Madrid: Fundación Universitaria Española.

Oliver, J. A. (2012). El teatro lírico en Granada en el siglo XIX. (Tesis Doctoral). Granada: Universidad de Granada.

Oliver, M. S. (1901). Mallorca durante la primera revolución (1808 a 1814). Palma: Imprenta de Amengual y Muntaner.

Olmos, A. M. (Ed.) (2017). Papeles Barbieri. Teatro de los Caños del Peral, 12 vols. Madrid: Discantus.

Palencia, A. (1996). Música sacra y profana en Alicante: la capilla de música de San Nicolás. ss. XVIXVIII. Alicante: Instituto de Cultura Juan Gil Albert.

Pascual, N. (2020). «Porque mi amor es sueño, y es delirio»: Propuesta de recuperación musical del drama pastoral La Flora (Valencia, 1735). Cuadernos de Investigación Musical, (9), pp. 5-40. http://doi.org/10.18239/invesmusic.v0i9.2238.

Peñas, M.C. (1996). Los Acuña, una familia de músicos. Revista de Musicología, 19, pp. 179208.

Pérez Giménez, J. I. \& Pérez Giménez, V. (2009). José Morata García (1769-1840), maestro de capilla de la Seu. Caminem Junts. Colegiata de Santa María de Xàtiva.

Radomski, J. (2000). Manuel Garcia (1775-1832): Chronicle of the Life of a Bel Canto Tenor at the Dawn of Romanticism. Oxford: Oxford University Press.

Revilla, J. de la (1899): Vida artística de Isidoro Máiquez: Madrid: Medina y Navarro editores.

Rodríguez, F. (2012). Miguel Domingo, un huracán liberal en Palma de Mallorca. Memòries de la Reial Acadèmia Mallorquina d'Estudis Genealògics, Heràldics i Històrics, 22. Palma de Mallorca: Reial Acadèmia Mallorquina d'Estudis Històrics, Genealògics i Heràldics, pp. 167-185. 


\section{JOSÉ GABRIEL GUAITA GABALDÓN}

Rodríguez, F. (2013). La «impía» imprenta y librería mallorquina de Miguel Domingo (18101814). Cuadernos de Ilustración y Romanticismo, 19, pp. 365-390.

Romero, A. \& Moreno, A. (2006). Manuel García: de la tonadilla escénica a la ópera española (17751832). Cádiz: Servicio Publicaciones UCA.

Ros, V. (2001). Obras para tecla de Tomás Ciurana. Valencia: Diputació de València [Piles, impresión].

Ruiz de Lihory, J. (1903 [1987]). La música en Valencia: diccionario biográfico y crítico. Valencia: Doménech [1987, ed. facsímil librerías París-Valencia].

Sala, J.M. (1999): Cartellera del teatre de Barcelona: 1790-1799. Montserrat: Publicacions de l'Abadía de Montserrat.

Saldoni, B. (1868-1881). Diccionario biográfico-bibliográfico de efemérides de músicos españoles, 4 vols. Madrid: Antonio Pérez Dubrull [1995, ed. facsímil. Valencia, Librerías París-Valencia].

Saura, A. (2008). Teatro y teatro francés traducido en el Madrid de 1808: una aproximación. Anales de filología francesa, 16, pp. 205-221.

Segarra, T. (1862). Poesías Populares. Munich: F. A. Brockhaus.

Serrano, J. E. (1899). Reseña histórica en forma de diccionario de las imprentas que ban existido en V alencia desde la introducción del arte tipográfico en España basta el año 1868: con noticias bio-bibliográficas de los principales impresores / por José Enrique Serrano Morales. Valencia: F. Domenech.

Subirá, J. (1973). Variadas versiones de libretos operísticos. Madrid: CSIC.

Thomason, Ph. B. (2005). El Coliseo de la Cruz, 1736-1860: estudio y documentos. Woodbridge: Tamesis Books.

Viardot, L. (1841). Estudios sobre la bistoria de las instituciones, Literatura, Teatro y Bellas Artes. Logroño: Ruíz.

Weinmann, A. (2001). Hoffmeister, Franz Anton. Grove Music Online. Recuperado el 23.03.2020 de https://www.oxfordmusiconline.com/grovemusic/view/10.1093/gmo/9781561592 630.001.0001/omo-9781561592630-e-0000013162

Fecha de recepción: 08/02/2021

Fecha de aceptación: 15/12/2021 